\title{
Las series anuales de precipitación más largas de Chile: estudio y enseñanzas
}

\section{The annual longest precipitation series over Chile: study and consequences}

\author{
Juan José Sanz Donaire*
}

\section{INTRODUCCIÓN}

El Chile continental, de un área de $756.102 \mathrm{~km}^{2}$, se extiende a lo largo de casi $40^{\circ}$ de latitud, desde el extremo norte a $17^{\circ} 29^{\prime} \mathrm{S}$ hasta el extremo meridional a 56 32'S. Obviamos las reclamaciones territoriales que llegarían hasta el Polo Austral, por lo que se verificaría el carácter tricontinental del país (América, Oceanía y Antártida). De él se realiza en este trabajo un estudio de las series instrumentales de precipitación más largas que se han podido recopilar con el fin de establecer, en el caso de existir, las pautas de su comportamiento que podrían ayudar a comprender mejor su evolución, con ánimo de aventurar posibles continuidades en el futuro. Hay estudios previos como el de Santibáñez (1997) en el que se trabajó con medias móviles.

Los datos analizados corresponden básicamente a dos fuentes diferentes: los Anuarios Meteorológicos de Chile y la base de datos del National Oceanic and Atmospheric Administration (en adelante NOAA). Las informaciones que aportan ambas fuentes no siempre coinciden, por lo que se deben considerar errores de diferente magnitud (grandes y pequeños) en los datos facilitados por éstas. A modo de ejemplo, he aquí los datos de 1959 de Curicó, a partir de los valores mensuales en décimas y el total anual en milímetros (cuadro 1).

\footnotetext{
* Departamento de Análisis Geográfico Regional y Geografía Física, Universidad Complutense de Madrid (jjsanzdo@ghis.ucm.es).
} 
CUADro 1

DATOS DE 1959 DE CURICÓ

\begin{tabular}{llllllllllllllllll}
\hline Estación & Año & En & Feb & Mar & Abr & May & Jun & Jul & Ago & Spt & Oct & No & Di & An \\
\hline $\begin{array}{l}\text { Curicó } \\
\text { NOAA }\end{array}$ & 1959 & 410 & 30 & 320 & 1.790 & 820 & 1.390 & 1.870 & 290 & 270 & 450 & 0 & 0 & 764 \\
$\begin{array}{l}\text { Curicó } \\
\text { Anuario }\end{array}$ & 1959 & 400 & 34 & 320 & 1.790 & 820 & 1.390 & 1.870 & 290 & 280 & 440 & 0 & 0 & 763,4 \\
\end{tabular}

Fuente: elaboración propia a partir de la base de datos del NOAA y de los Anuarios Meteorológicos de Chile.

La diferencia más importante es que la base de datos del NOAA, sin tener en cuenta las afirmaciones de los preámbulos de los Anuarios, toma el signo «-» como «no hay observación», esto es «-9999» en su semiología, cuando para ello reserva el original, el blanco « ». Por ello, el Anuario de 1920 incluye en la Introducción, firmada por el Director del Instituto Central Meteorológico y Geofísico de Chile, Carlos Henríquez, la siguiente aclaración: «En la misma forma en que se publicó el anuario de 1919, se hace el correspondiente a 1920. Solamente en las lluvias se agrega una columna para los días de agua caída de 1,0 mm o más. De este modo desaparecen, en gran parte, las irregularidades, que se notan en las anteriores publicaciones, al comparar las sumas de los días de lluvia en los puntos vecinos, ya que algunos observadores no miden las pequeñas precipitaciones correspondientes a garúas, neblinas, etc.»

En el anuario de 1952, por ejemplo, se lee literalmente: «Las cantidades de lluvia medidas están aproximadas al entero, no así cuando la precipitación ha sido inferior a $1 \mathrm{~mm}$, en que se representa con décimas. Además, se ha convenido en representar con una línea (-) la suma de los meses sin lluvia; por cero cuando ésta es menor de una décima de milímetro y en blanco en los meses en que no hubo observaciones...»

Llama la atención que a veces los valores transcritos a NOAA no tengan esto en cuenta, sino que interpretan el signo «guión medio» (-) como falta de observación.

También se ha producido una cierta evolución en los datos y en los organismos. En este sentido, el anuario de 2004 y siguientes (hasta el último de 2010) ofrece la siguiente cronología del Servicio Meteorológico Nacional:

- 24 de octubre de 1868: se estableció la Oficina Central de Meteorología, dependiente de la Universidad de Chile. 
- 1870: se publicó en Santiago, el primer Anuario de la Oficina Central de Meteorología. Contenía un resumen de las Observaciones Meteorológicas ejecutadas en el país durante el año 1869.

- 26 de marzo de 1884: se decretó oficialmente el establecimiento de un Servicio de Observaciones Meteorológicas simultáneas, cuya realización corrió a cargo de los encargados de los registros meteorológicos, conforme a las instrucciones impartidas y transmitidas vía telégrafo al Observatorio Nacional.

- 1910: se unificaron las actividades meteorológicas y se creó el Instituto Central Meteorológico y Geofísico, cuyo Programa contempló la mejora del instrumental y el aumento del número de estaciones, con el fin de reunir elementos que permitieran conocer el clima del país.

- 31 de mayo de 1928: se creó la Oficina Meteorológica de Chile como institución dependiente del Ministerio de Marina, asignándole el carácter de Organismo Oficial y Rector en materia de meteorología nacional.

- 1948: se aprobó el decreto que colocó a la Institución bajo la tutela de la Fuerza Aérea de Chile.

- 9 de mayo de 1957: la Oficina Meteorológica de Chile ingresó en la Organización Meteorológica Mundial.

- 8 de mayo de 1973: se aprobó el decreto que estableció que la Oficina Meteorológica de Chile se denominaría en lo sucesivo como Dirección Meteorológica de Chile. Así mismo se creó el Banco Nacional de Datos Meteorológicos, cuya función fue la recopilación y la difusión de toda la información meteorológica.

- 30 de diciembre de 1990: se publicó el primer Anuario de la Dirección Meteorológica de Chile obtenido íntegramente mediante sistemas computacionales.

Las estaciones elegidas en esta primera aproximación han sido casi una por cada región administrativa, con el fin de obtener un registro como representante de los análisis pluviométricos generales que se desea realizar (la lista de localidades figura en el cuadro 2). Con ello se ha logrado un doble objetivo: disponer de un número suficientemente elevado de estaciones y mostrar la diversidad del amplísimo territorio chileno, que comprende casi medio cuadrante del meridiano terrestre.

Los datos se han tomado de los Anuarios Meteorológicos Chilenos, disponibles desde 1920 y, para fechas anteriores, se ha recurrido a la base de datos del NOAA. Como muestra de las dificultades que presenta la fuente oficial (el Anuario Chileno), se exponen a continuación algunos ejemplos relativos a las estaciones de Iquique, Copiapó, Isla de Pascua, Curicó y Osorno. 
CUADRO 2

LISTA DE ESTACIONES CHILENAS ELEGIDAS PARA EL PRESENTE TRABAJO

\begin{tabular}{cccc}
\hline Región & Denominación & Localidad & Serie \\
\hline XV & Arica y Parinacota & Arica & $1920-2011$ \\
I & Tarapacá & Iquique & $1899-2011$ \\
II & Antofagasta & Antofagasta & $1920-2011$ \\
III & Atacama & Copiapó & $1925-2008$ \\
IV & Coquimbo & La Serena & $1869-2011$ \\
V & Valparaíso & Isla de Pascua & $1939-2011$ \\
& Metropolitana & Santiago & $1867-2011$ \\
VII & Maule & Isla de Juan Fernández & $1902-2011$ \\
VII & Maule & Curicó & $1920-2011$ \\
VIII & Bío Bío & Concepción & $1912-2011$ \\
IX & Araucanía & Temuco & $1912-2011$ \\
X & Valdivia & Valdivia & $1853-80,1900-2011$ \\
XI & Los Lagos & Osorno & $1920-2011$ \\
XI & Aysén del General Carlos & Puerto Montt & $1862-73,1888-1902$, \\
& Ibáñez del Campo & & $1907-2011$ \\
XII & Magallanes y la Antártica & Punta Arenas & $1888-2011$ \\
\hline & Chilena & & \\
\hline
\end{tabular}

Fuente: elaboración propia.

\section{Estación de Iquique}

Desde 1920 sabemos que se trata de la estación de Isla Serrano, aunque se haya consignado como Iquique Cavancha. En 1961 y siguientes se ha tomado la precipitación de Iquique, a $20^{\circ} 13^{\prime} \mathrm{S}, 70^{\circ} 09^{\prime} \mathrm{W}, 9 \mathrm{~m}$ de altitud. Los últimos años corresponden a la estación Iquique Diego Aracena a 20 $32^{\prime} \mathrm{S}, 70^{\circ} 11^{\prime} \mathrm{W}, 52 \mathrm{~m}$ de altitud. No obstante, considero que las diferencias de localización apenas inciden en el ritmo anual que se desea estudiar aquí. 


\section{Copiapó}

No hay datos en los Anuarios de 1920 a 1924, pues sólo se halla cercana la estación de «Caldera», situada en la costa, lo que no la hace recomendable para su utilización. La distancia que las separa es de $58 \mathrm{~km}$ y casi $700 \mathrm{~m}$ de altitud. La serie comienza en 1925, para una estación localizada a $27^{\circ} 21^{\prime} \mathrm{S}, 70^{\circ} 21^{\prime} \mathrm{W}, 370 \mathrm{~m}$, que mantiene latitud y longitud pero no altitud, pues pasa a ser de $380 \mathrm{~m}$ a partir de 1929. ¿Ha cambiado la localización de la estación o se ha corregido la altitud?

Desde 1935 la altitud se establece en $388 \mathrm{~m}$. Vuelvo a hacerme la misma pregunta. En 1939 la altitud consignada es de $380 \mathrm{~m}$, por lo que se debe tratar de un redondeo y no de un cambio de posición. Desde 1946 las estaciones están en el Aeródromo, Servicio Agrónomo y E.A.P. (Empresa de Agua Potable) con diversa localización pero cantidades de precipitación muy similares (tomo Serv. Agr. como continuación).

En 1950 desaparece el Aeródromo, manteniéndose el Ser. Agr. y otro Copiapó sin especificar, tal y como se ve en el tabla 1.1.

En 1951 el Aeródromo ha rebajado su altitud, lo mismo que el Servicio Agrónomo y la E.A.P. (tabla 1.2).

En 1955 falta el mes de diciembre en cualquiera de las localizaciones. En 1956 ha ascendido de categoría la estación pluviométrica a termopluviométrica, por lo que se recogen más datos. Se mantiene a $370 \mathrm{~m}$ de altitud. Luego se pondrá la altitud del barómetro: 397 m, con longitud de 70²0'W. En 1958 vuelve a salir de estación termopluviométrica a pluviométrica, sin altitud. En 1959, retorna a la consideración de termopluviométrica, su altitud es de $370 \mathrm{~m}$. En 1959, ídem, pero la altitud del barómetro $\mathrm{H}_{\mathrm{b}}$ (sic) es de $370 \mathrm{~m}$. En el anuario del 1963 aparece longitud $71^{\circ} 21^{\prime} \mathrm{W}$. En 1964 se consigna en los resúmenes de estaciones pluviométricas, que no en estaciones completas (tabla 1.3).

Para 1965 aparece entre las series completas Copiapó (Chamonate) con idéntica localización, salvo por la altitud ( $283 \mathrm{~m})$; los datos se toman de ella. En los resúmenes anuales de las estaciones pluviométricas aparece literalmente (tabla 1.4).

En los resúmenes de 1966 se leen los siguientes datos (tabla 1.5).

En 1967 la estación completa, Chamonati (sic en el original), tiene una altitud de $370 \mathrm{~m}$. ¿Era un error el valor anterior? Probablemente sí. En el resumen aparece, para Copiapó Fach (tabla 1.6).

Desde 1968 en adelante utilizo los datos de la base de datos del NOAA, salvo en faltas, pues son casi idénticos (redondeados a enteros). Desde 1983 comienza como estación pluviométrica una «particular»: $27^{\circ} 22^{\prime} \mathrm{S}, 70^{\circ} 18^{\prime} \mathrm{W}$, $350 \mathrm{~m}$ (tabla 1.7). 


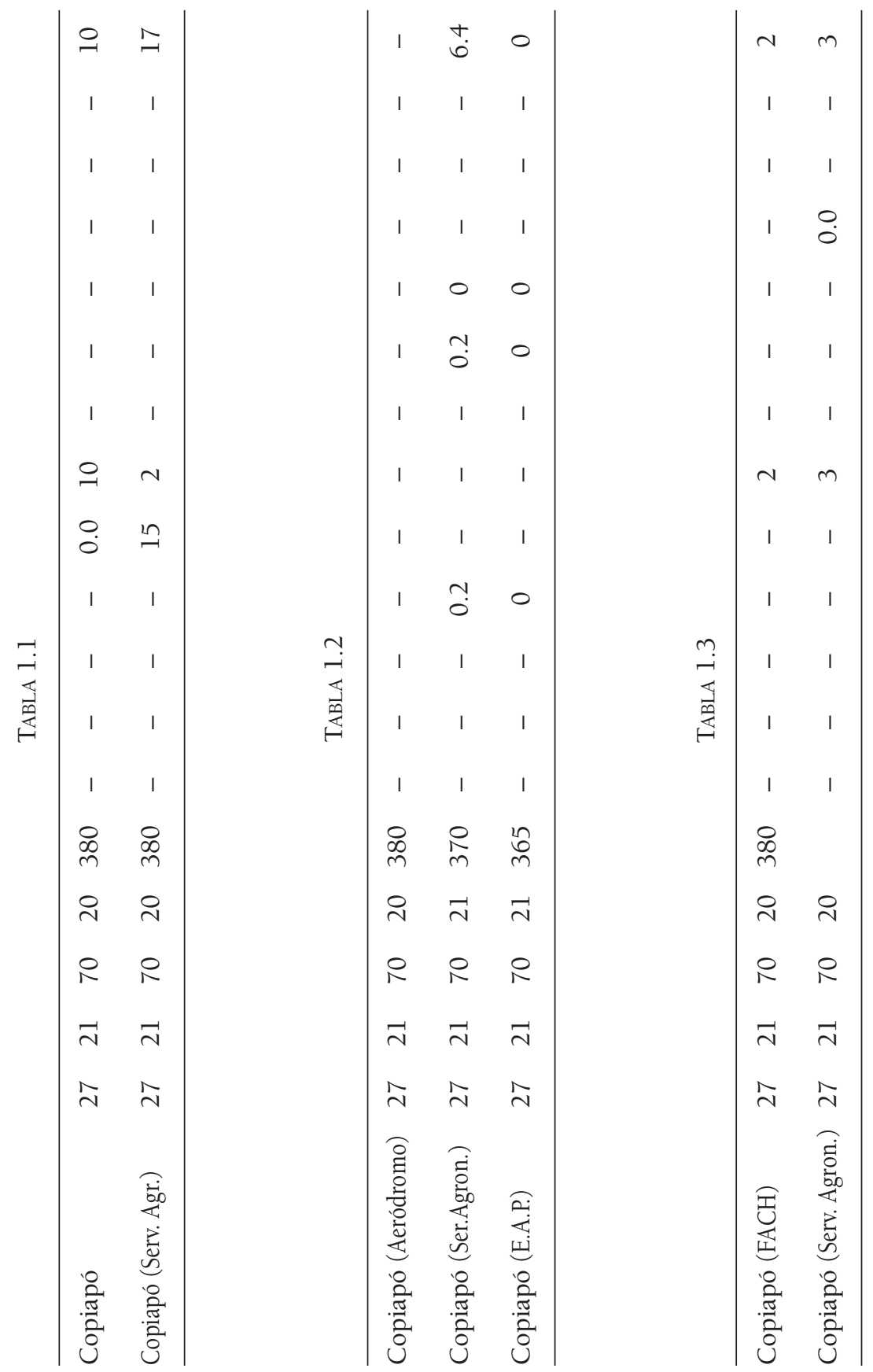

Estudios Geográficos, Vol. LXXIII, 273, pp. 625-656, julio-diciembre 2012 ISSN: 0014-1496, eISSN: 1988-8546, doi: 10.3989/estgeogr.201222 

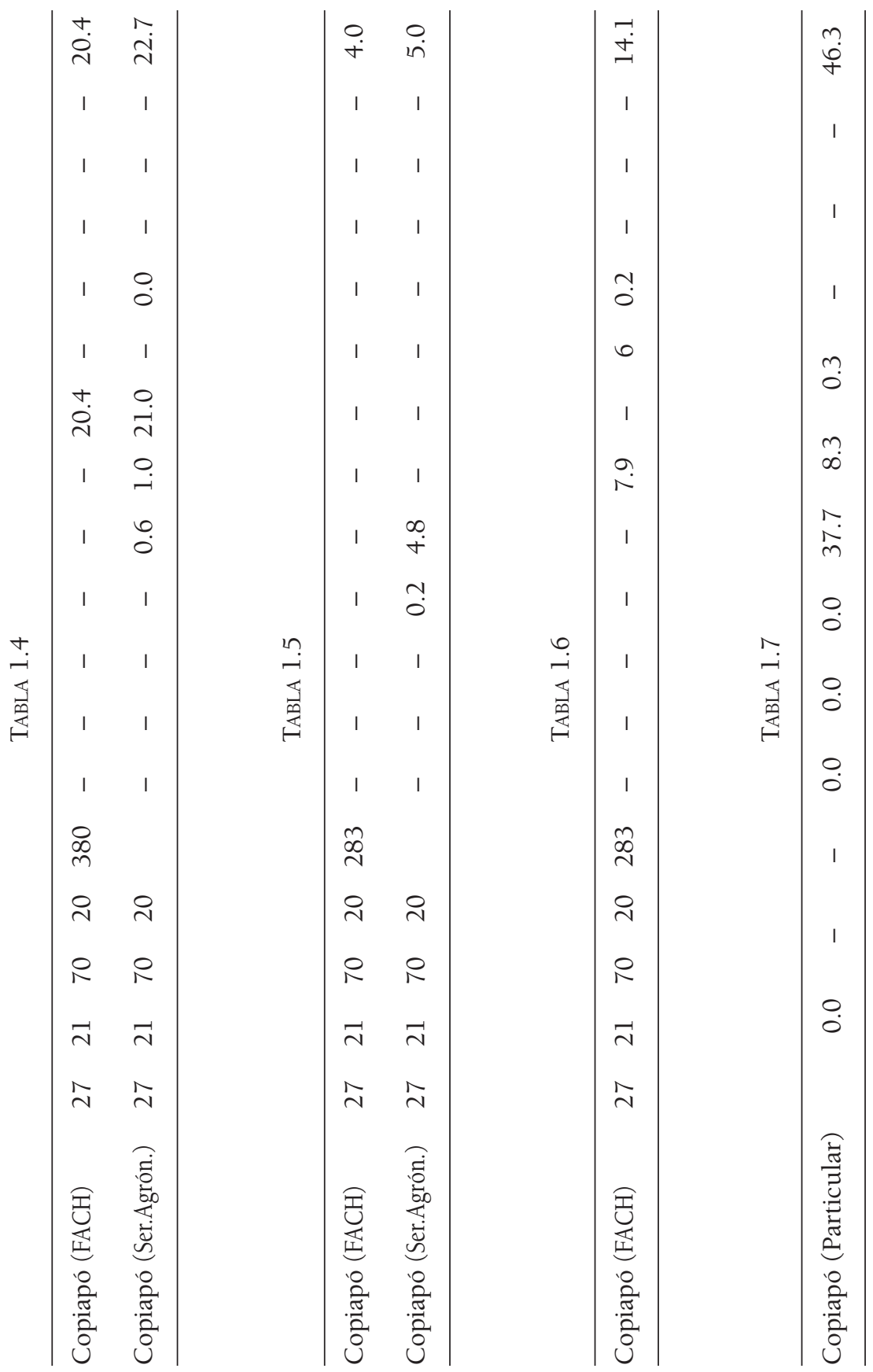

Estudios Geográficos, Vol. LXXIII, 273, pp. 625-656, julio-diciembre 2012 ISSN: 0014-1496, eISSN: 1988-8546, doi: 10.3989/estgeogr.201222 
En 1988 no hay datos de estación completa: se sustituye por «Particular», lo que se mantiene hasta 1991. En el año 1992 vuelve a haber datos en las estaciones completas. 2005: «Particular». No hay datos de Copiapó en 2006 ni en 2007. En 2008 y 2009 aparece como Copiapó particular, pero este último año no está completo. En 2010 está una estación llamada Copiapó Desierto de Atacama, literalmente: «COPIAPO DESIERTO DE ATACAMA, Región III, $27^{\circ}$ $16^{\prime} \mathrm{S}, 70^{\circ} 47^{\prime} \mathrm{W}, 204 \mathrm{~m}$ de altitud», que no agrego a los datos anteriores.

\section{Isla de Pascua}

En principio corresponde a la estación de Mataveri, localizada en $27^{\circ} 09^{\prime} \mathrm{S}$, $109^{\circ} 25^{\prime} \mathrm{W}, 51 \mathrm{~m}$ de altitud.

En los Anuarios de 1942 y de 1947 no está disponible. En 1972 no hay datos en el Anuario para esta estación. Para algunos años no sólo se ofrece el dato para la estación de Mataveri, sino también para el Fundo Vaitea, en las coordenadas $27^{\circ} 06^{\prime} \mathrm{S}, 109^{\circ} 21^{\prime} \mathrm{W}, 170 \mathrm{~m}$ de altitud. Lo mismo ocurre en 1993 y en 1997.

\section{Estación de Curicó}

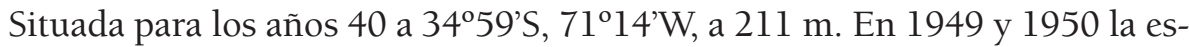
tación pasa a $34^{\circ} 58^{\prime} \mathrm{S}, 71^{\circ} 13^{\prime} \mathrm{W}$, a $225 \mathrm{~m}$-que en 1966 se denomina Curicó FACH-, manteniéndose luego, desde 1959 en adelante, en la misma localización. No existía en el anuario de 1924 ni en el de 1952 a 1958, por lo que la

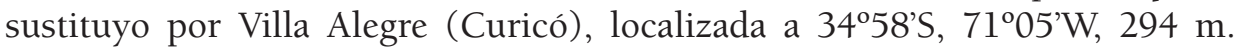
Dado que, a partir de 1959, la comparación entre las estaciones del NOAA y del Anuario Chileno prácticamente coinciden (con diferencias sólo de décimas de milímetro al año), se opta por mantener como válidos los valores del NOAA, si bien se complementan las lagunas con el Anuario Chileno. Para el periodo posterior a 1981 no hay datos para esta estación ni en NOAA, ni en el Anuario, por lo que se sustituye por Curicó General Freire situada a 34 $58^{\prime} \mathrm{S}$, $71^{\circ} 14^{\prime} \mathrm{W}, 228 \mathrm{~m}$ de altitud.

\section{Estación de Osorno}

Los datos de la estación de Osorno se han construido desde 1920 a partir de diversas fuentes. Para ese año inicial se ha tomado la precipitación de Chahuilco, a sólo 3,5 km de distancia hacia el noroeste. A partir de 1921 las 
cifras están tomadas de la estación de San Pablo Osorno. Falta en el anuario de 1925. En el de 1929 ya aparecen diferenciados Osorno $\left(40^{\circ} 35^{\prime} \mathrm{N}, 73^{\circ} 09^{\prime} \mathrm{W}\right.$, $27 \mathrm{~m}$ ) de San Pablo $\left(40^{\circ} 25^{\prime} \mathrm{N}, 73^{\circ} \mathrm{W}, 60 \mathrm{~m}\right.$ ) por lo que se opta por el primero. Se retoma la serie desde 1931 para San Pablo.

Cuando no se ha podido obtener la cifra de Osorno (E.A.P.) se ha tomado en su defecto Cañal Bajo. Atención a las denominaciones también de Osorno Ovejería, junto a Cañal Bajo y San Pablo (en 1983).

Como se observa de estos ejemplos queda una amplia labor pendiente por hacer por el organismo competente en la materia.

El trabajo ha consistido en la confección de los datos de precipitación de las estaciones antes mencionadas, que, no sin ardua tarea, ha devenido una serie casi completa. Se ha optado en esta primera fase por no completar mediante ninguna técnica de proximidad estadística o geográfica la serie anual ni siquiera cuando el año esté casi completo (por ejemplo, a falta de un único mes). Por lo tanto, se ha trabajado, únicamente, con los valores totales anuales cuando éstos se presentan completos.

\section{RÉGIMEN INTERANUAL DE PRECIPITACIÓN}

El estudio se ha producido mediante sucesivas aproximaciones: en primer lugar, el análisis de toda la serie (cuadro 3), en la que se destacan los valores de la pendiente de la recta de regresión calculada, así como el número de años registrados y la significación estadística, mediante el valor $p$. Como se sabe si éste es igual o inferior a 0,10, la significación estadística supera el 90\%; si baja de 0,05 rebasa el $95 \%$ de probabilidad y si transgrede el 0,01 sube la probabilidad al 99\%. También se han agregado otros estadísticos: media (en milímetros), coeficiente de variación (en porcentaje) y coeficiente de asimetría o sesgo tipificado, que completan de caracterización de las distintas estaciones meteorológicas. Debo destacar que prefiero el coeficiente de variación a la desviación estándar ya que, al ir expresado en porcentaje, es adimensional, y esto supone una ventaja significativa al trabajar con estaciones de total anual de precipitación muy diferentes, como se observa en la columna que presenta la media de todo el período registrado.

Siendo el número de años registrados de al menos setenta (Isla de Pascua) y alcanzando en Valdivia los ciento cuarenta, puede hablarse ya con propiedad de un análisis climático, en el que se observa la diversidad intrínseca a las precipitaciones. Tratadas las serie en su conjunto, es llamativo que una regresión lineal sea significativa, al menos al 95\%, en 9 de las 15 estaciones considera- 
das. Más aún: es significativa al 99\% en 5 de los casos, lo que representa el $33 \%$ de los casos totales. No obstante, su distribución espacial bien merece algún comentario: la máxima significación se halla en los extremos norte y sur del clima árido (Arica y Copiapó, respectivamente), quedando Antofagasta con significación al 95\%, pero Iquique, la serie más longeva de todo el norte chileno, arroja la mínima significación de toda la República (gráfico 1). Este comportamiento pudiera reflejar que los 20 datos iniciales de la serie son muy distintos al resto, hasta el punto de condicionar el resultado tan profundamente. Pero no es el caso, sino que la razón hay que buscarla en una recta casi paralela al eje de las "X», la variable tiempo, luego sin significación, a lo que se une la máxima desviación proporcional interanual. Aunque con valores exiguos podría afirmarse que la tendencia es a un incremento, si bien mínimo, de la precipitación en este sector norteño.

GRÁFICO 1

TOTALES DE PRECIPITACIÓN ANUAL EN IQUIQUE

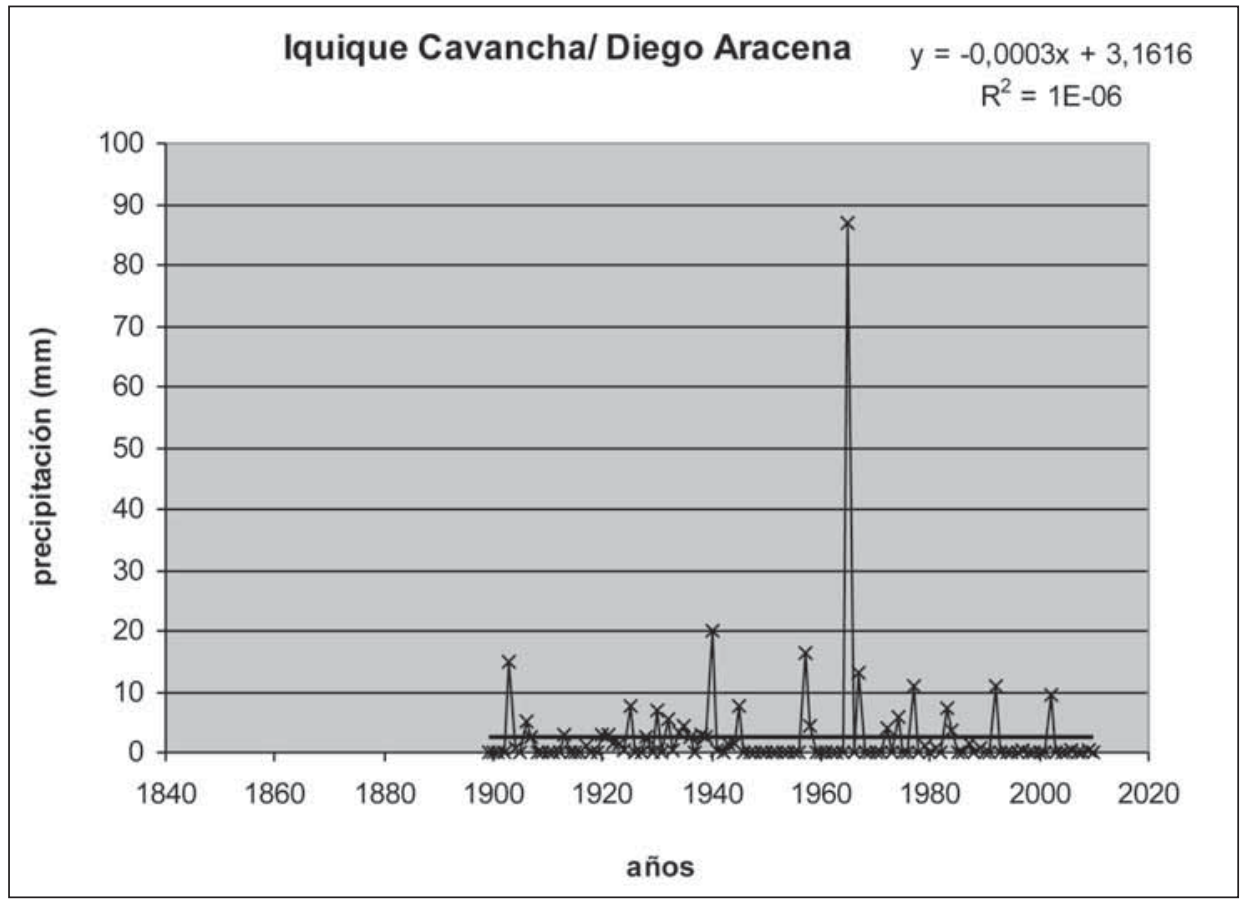

Fuente: elaboración propia. 
En el área central chilena — La Serena, Santiago (gráfico 2) y Curicó-, las precipitaciones descienden y, a tenor de la significación comúnmente admitida del 95\% de probabilidad, lo seguirán haciendo en el inmediato futuro (i?) de continuar esta pauta, en cantidades de varias unidades porcentuales. Debe admitirse que el valor de probabilidad del ajuste de la recta está bastante próximo a la significación (83\%), que no suele aceptarse científicamente como válido, aunque no debe despreciarse, máxime si se ve acompañado de otros valores geográfica y estadísticamente cercanos a él.

GRÁFICO 2

TOTALES DE PRECIPITACIÓN EN SANTIAGO DE CHILE

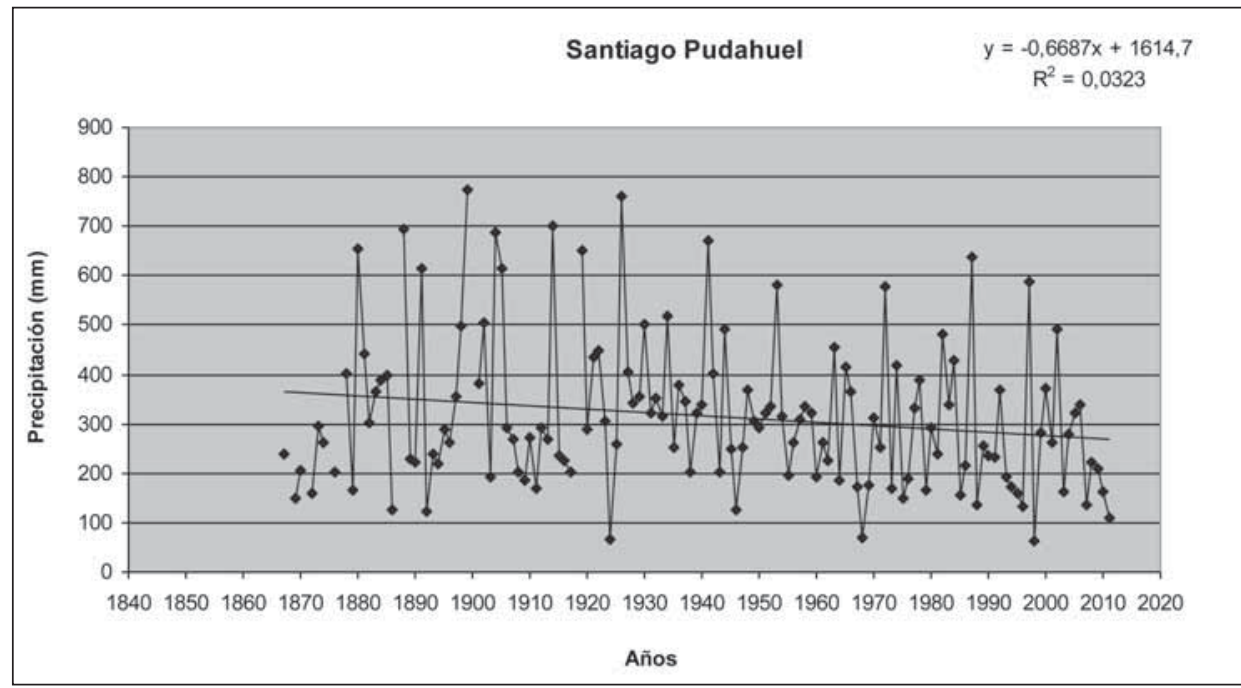

Fuente: elaboración propia.

Mención aparte merecen las islas: ambas sin significación estadística, lo que podría explicarse por la reiterada oscilación entre valores máximos y mínimos, con series un tanto cortas para el conjunto estudiado, muestran un ascenso mayor de las precipitaciones anuales en Pascua que en Juan Fernández (gráfico 3), sin duda asociado al carácter más oceánico de la primera, entre otros factores, por la mayor lejanía al continente $(3.500 \mathrm{~km}$ de la primera frente a los algo más de 600 de la segunda), y su localización respecto de los centros de acción atmosféricos, especialmente del anticiclón surpacífico. 
GRÁFICO 3

PRECIPITACIÓN EN LA ISLA DE JUAN FERNÁNDEZ O DE ROBINSON CRUSOE

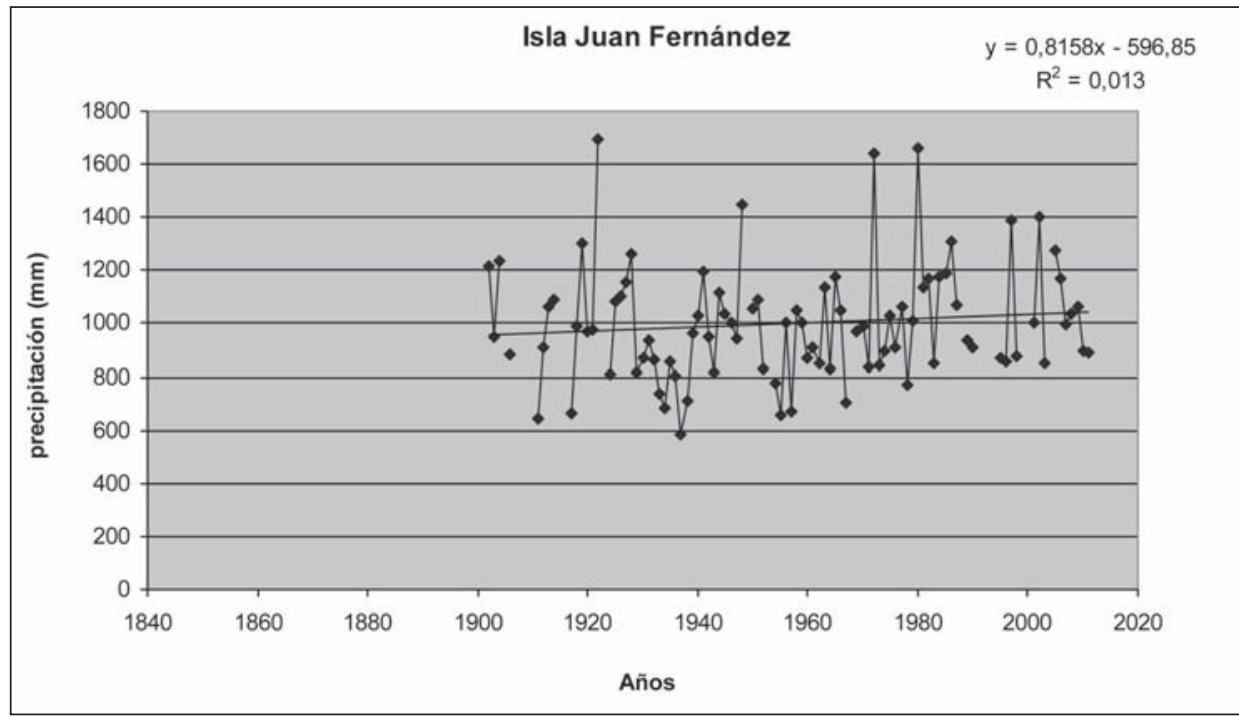

Fuente: elaboración propia.

GRÁFICO 4

EVOLUCIÓN ANUAL DE LA PRECIPITACIÓN EN VALDIVIA

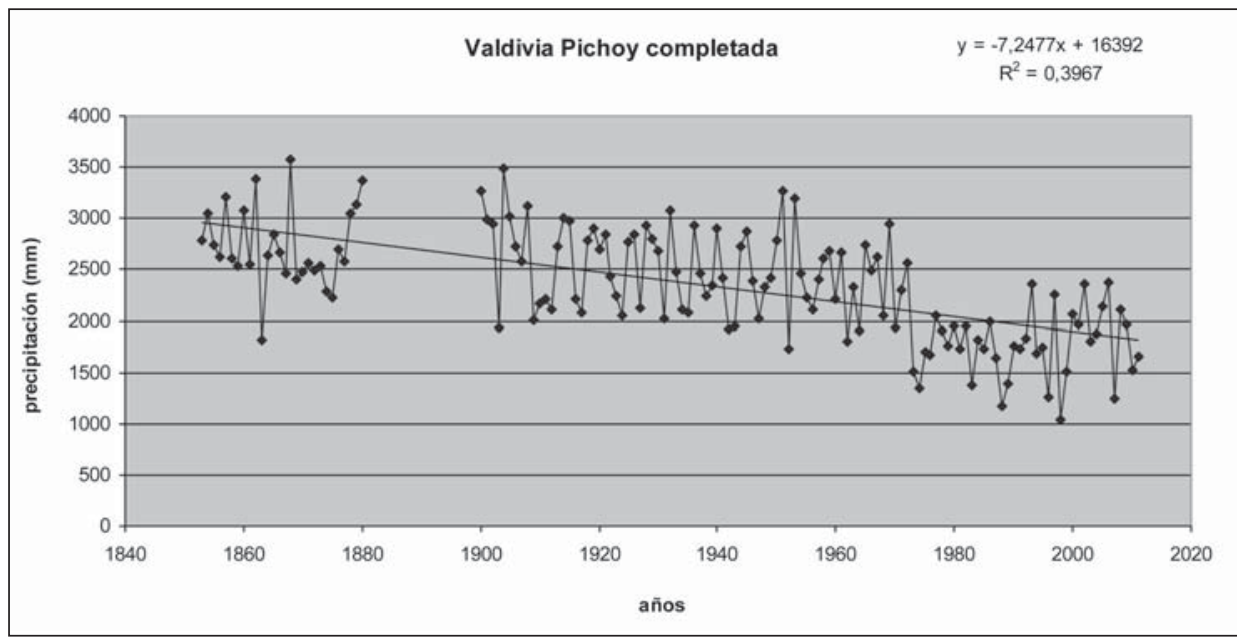

Fuente: elaboración propia.

Estudios Geográficos, Vol. LXXIII, 273, pp. 625-656, julio-diciembre 2012

ISSN: 0014-1496, eISSN: 1988-8546, doi: 10.3989/estgeogr.201222 
La pauta de las estaciones continentales húmedas es uniforme: pérdida de precipitación con el paso del tiempo (coincidiendo con Bown, 2005), pero con la excepción de Osorno que gana mínimamente. Al ser ésta la estación más corta del registro, también debe influir en el resultado, pues las restantes localidades al menos igualan el centenar de años. Concepción y Temuco muestran un descenso importante desde 1940; Valdivia se hunde desde 1972 - y ello está presente no sólo en la estación de Valdivia Pichoy, sino en la de la ciudad- (gráfico 4) y Puerto Montt, además de partir de unos valores decimonónicos muy elevados (creíbles, ya que también en otras estaciones con registro en esos años existe el mismo comportamiento, por demás registrado en muchos lugares del mundo como la India o Centroeuropa), mantiene un considerable descenso desde 1971. Esos valores iniciales tan altos, son también responsables de la alta significación estadística (gráfico 5).

GRÁFICO 5

EVOLUCIÓN ANUAL DE LA PRECIPITACIÓN EN PUERTO MONTT

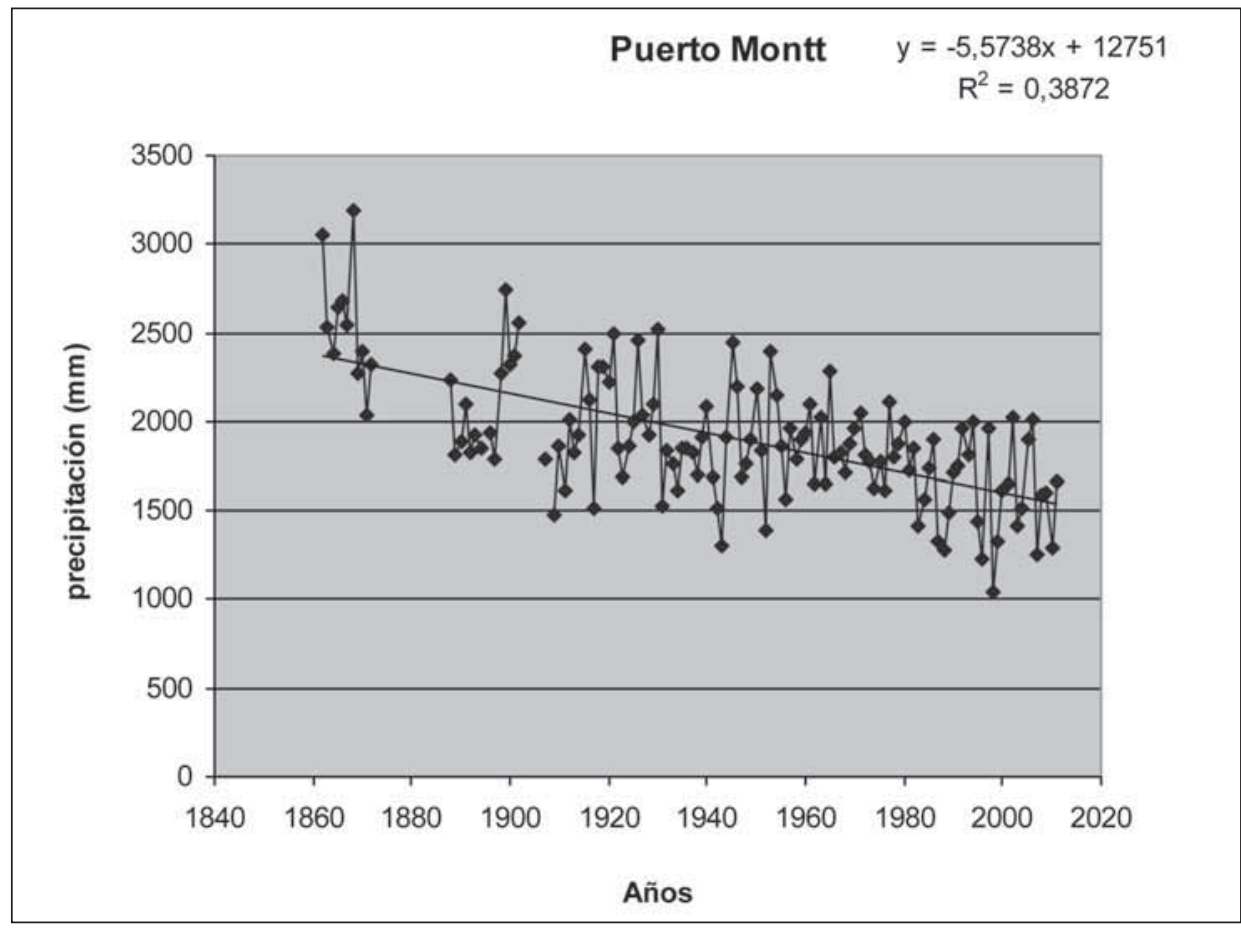

Fuente: elaboración propia. 
Punta Arenas se desvía de sus compañeras, muestra ascenso —al contrario que las estaciones hiperhúmedas - y carece de significación (gráfico 6).

GRÁFICO 6

EVOLUCIÓN TEMPORAL DE LA PRECIPITACIÓN EN PUNTA ARENAS

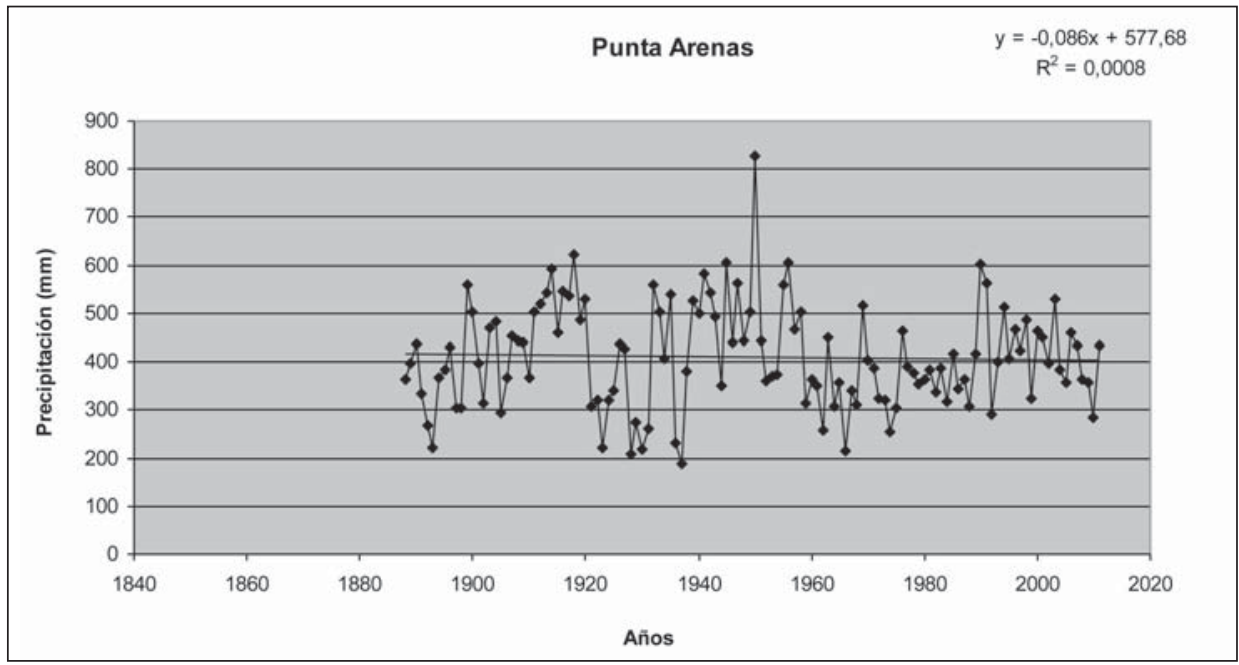

Fuente: elaboración propia.

Del resto del cuadro de toda la serie destacaría lo obvio: en la columna de precipitación media, la máxima diversidad entre las estaciones, pues se exponen datos de climas desérticos $-\mathrm{y}$ probablemente del desierto absoluto del Globo-, a los hiperhúmedos de las latitudes medias-altas. No obstante, el extremo meridional de Punta Arenas ya ofrece una reducción muy notable de las precipitaciones, una particularidad que también estará presente en otras magnitudes.

Los coeficientes de variación también ofrecen la misma diversidad que las medias: máximos muy sobresalientes en el extremo norte y valores mínimos en los lugares continentales de influencia oceánica, desde el mínimo de Osorno a Puerto Montt, Temuco y Valdivia, amén de las islas de Juan Fernández y de Pascua.

La misma variedad se expone en cuanto a la asimetría: valores extremos positivos en los ámbitos desérticos y subdesérticos, valores cercanos a una distribución normal en lo oceánico y valores negativos en el clima templado hú- 
medo. El lejano sur chileno vuelve a sesgos positivos. Omito los valores de los observatorios intermedios que ostentan características de transición.

Como el estudio se centra en la evolución temporal de las precipitaciones, carece de sentido una comparación entre las estaciones, su agrupación por métodos de clúster, etc.

\section{El ESTUdio DE LAS SERIES AJUSTADAS A COMIENZOS DE PERÍODOS HOMÓlOGOS}

Ante la realidad de series dispares en cuanto al año de su comienzo, se ha trabajado con preferencia con las que se iban incorporando al acervo de las chilenas, a tenor de los treintenios CLINO (Climatogical Normals). Con ello se pretende unificar las series de las distintas localidades a efectos de una comparación en condiciones homogéneas. Los resultados obtenidos también aparecen en el cuadro 3 y de ellos sobresalen las siguientes ideas:

1) Una contemplación total del cuadro muestra que la significación está muy ligada a la duración de la serie. Así en el período 1871-2011 las cuatro series que mantienen datos para estas fechas son estadísticamente significativas, dos al 99\% (las más meridionales) y las dos centrales al 90\%. Los cuatro casos tienen disminución de la lluvia registrada. Si se restringe el período de estudio al transcurrido desde 1901 a la actualidad (el último año incorporado es 2011), ya están representadas todas las estaciones excepto la Isla de Pascua, pero de las 14 estaciones sólo 4 no son significativas; se mantiene la significación máxima en 6 casos, intermedia en dos y una mínima. Al centrar el estudio entre 1931-2011 la significación total desciende a 8 del total de 15 estaciones, y aún se ve más menguada si el estudio se ciñe al período 1961-2011: sólo 5 estaciones significativas, de ellas 1 al máximo nivel y el resto a nivel medio.

2) Acorde con la pauta anterior, las estaciones que mantienen una significación estadística al máximo nivel suelen perder éste con el correr del tiempo, a excepción de Puerto Montt. Sorprende que Arica, con tan mínima cantidad de agua recogida, sea tan altamente significativa, a pesar de las grandes diferencias porcentuales de su escasa precipitación. Una vez más el sur chileno marca clara la disminución, con la salvedad del comportamiento inverso de Punta Arenas.

3) Las pautas que se vieron en toda la serie para las áreas húmedas se mantienen, incluso aunque la longitud de la misma se reduzca. Las tendencias negativas no muestran un claro comportamiento uniforme (cuantía 
de la subida o de la bajada) con el transcurso del tiempo: es más aleatorio que ajustable a un modelo.

4) Si se extrapolasen al futuro los datos acordes con la tendencia calculada, en algunos casos áridos el resultado sería incoherente, pues pronto no habría agua, e incluso el dato sería negativo, lo que matemáticamente es un resultado, pero es físicamente imposible. Por ello quiero llamar la atención sobre el hecho de que la estadística ofrece unos frutos que, en algunos casos, no pueden ser reales, como tampoco lo fueron en el pasado. Las crónicas históricas no hablan de condiciones muy diferentes de las actuales: el desierto, por ejemplo, ya era considerado tal durante las primeras expediciones de los españoles. Se impone por lo tanto un modelo más oscilante que tendente, al menos para tiempos de unos 500 años, a pesar de que la simplicidad del cálculo haya impuesto el uso de rectas de regresión para el período instrumental.

5) A este fin se intentará superar el modelo lineal para entrar en análisis temporales cíclicos.

\section{El ESTUDIO DE LAS SERIES CLINO DE PRECIPITACIÓN POR SEPARADO}

Parece oportuno estudiar las series CLINO por separado, teniendo en cuenta que son el modo habitual de trabajar con las series, incluso en precipitaciones aunque de antemano se pueda esperar un comportamiento bastante diferente de unos lapsos de tiempo a otros. Esto corrobora que tal vez fuera necesario un tiempo más largo para recoger adecuadamente la variabilidad natural de las precipitaciones, al menos en estos ámbitos, una aseveración que, teniendo en cuenta la extensión meridiana del territorio chileno, casi puede afirmarse para todo un cuadrante terrestre, y, por ende, a toda la Tierra.

Se ofrece un cuadro resumen (cuadro 4) de las principales características de las distintas series. En él se puede apreciar que de los 65 casos o períodos estudiados sólo 9 alcanzan alguna significación estadística: $6 \geq 95 \%$ (destacados en el cuadro por el sombreado más intenso e inversión del color de los números) y 3 entre 90 y 95\% (sombreados débilmente). Dos de esos casos, Isla de Pascua y Valdivia respectivamente, tienen sólo $10 \mathrm{u} 11$ años registrados de la totalidad de la treintena posible, lo que puede producir un espejismo o apariencia estadística, más que un dato robusto. Parece, sin embargo, lejos de toda duda que en el extremo septentrional hay un tiempo más seco durante el treintenio 1931-1960 y, que entre los años 1961-1990 la misma pauta, si bien más intensa, señorea en el área templadohúmeda del sur de la República (Valdivia, Osorno y Puerto Montt). 
Fuera de estos casos, con significación estadística igualada o superior al 90\%, se muestra lo habitual en el estudio de precipitaciones: una distribución aleatoria, a pesar de los numerosos y distintos climas analizados. Es interesante reseñar que son 37 las series completas de años (ya sea de 30 años en los primeros casos y de 21 en el último período considerado), lo que significa que los datos se han tomado con regularidad, una práctica que, lamentablemente, no siempre se lleva a la práctica. Las carencias suelen aparecer en los treintenios iniciales, lo que es lógico y hasta esperable. Destaca pues Chile por una organización seria, no siempre común en otros estados. La aleatoriedad se muestra con preferencia a través de los cambios de pendiente entre estaciones vecinas, sin aparente causa, ni constancia en el tiempo. La aleatoriedad es pues tanto espacial como temporal. Como ejemplo de las variaciones temporales tomamos la estación de Santiago (muy completa), en donde podemos comprobar las oscilaciones pluviométricas en treintenios seguidos: asciende considerablemente, asciende con suavidad, baja considerablemente, asciende con suavidad y baja considerablemente; la estación cercana de La Serena ni siquiera respeta las bajadas capitalinas, y los momentos de máxima subida, siempre muy moderados, tampoco coinciden en el tiempo. Otro tanto puede decirse de la comparación entre Puerto Montt y Osorno: con trayectorias separadas en los dos treintenios iniciales, se han reconciliado para los períodos del final. Para ahondar más en lo dicho: aunque Temuco y Concepción tienen idéntica trayectoria en cuanto al número de registros, los valores de las pendientes calculadas para la precipitación son contrarios durante los tres lapsos del comienzo, y sólo el último muestra coincidencia de tendencia.

\section{GRÁFICAS DE DESVIACIONES ACUMULADAS}

Las gráficas del régimen de precipitaciones en todas las estaciones resultan poco expresivas, por lo que se ha preferido un estudio de las curvas acumuladas como desviaciones respecto de la media. De la contemplación de las curvas acumuladas se hace patente lo que sigue:

1) Las curvas son bien dispares entre sí, y ello no sólo porque los períodos a los que se refieran sean igualmente distintos.

2) Comenzando a exponer de sur a norte se observa que Punta Arenas presenta subidas y bajadas, esto es, unos lapsos de tiempo húmedo y otros secos repetidos en tres «ciclos» seguros y un cuarto probable, a 


\section{GRÁFICO 7}

GRÁFICO DE DESVIACIONES ACUMULADAS DE PUNTA ARENAS CON INCLUSIÓN DE LA RECTA DE TENDENCIA Y SU COEFICIENTE DE DETERMINACIÓN

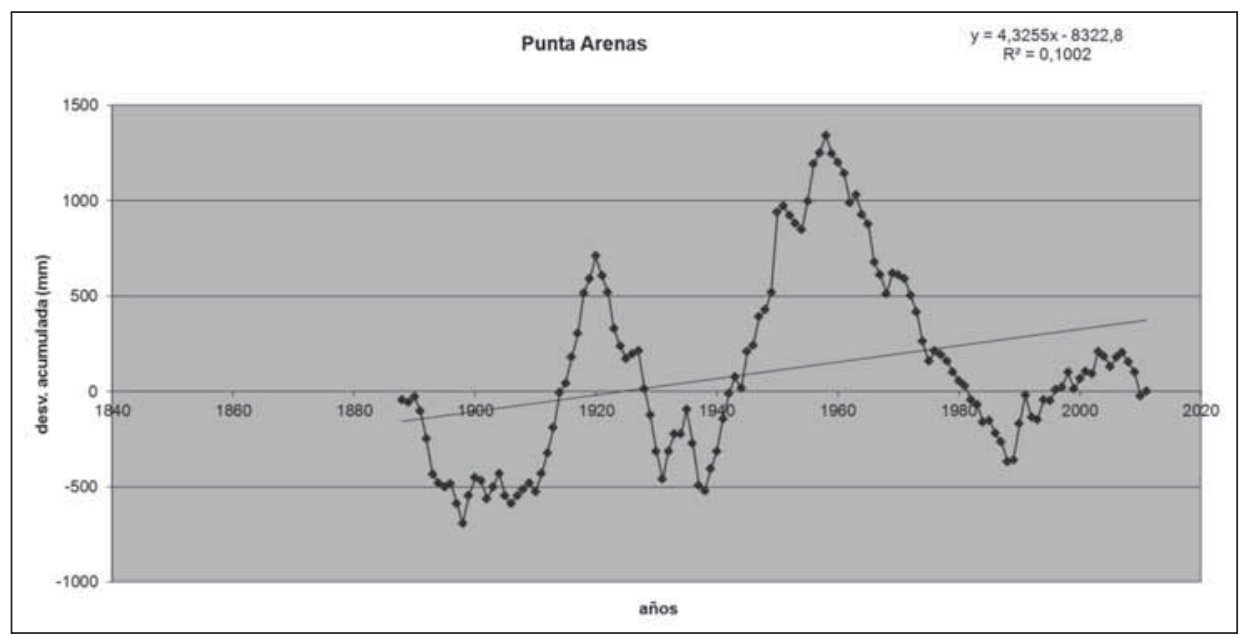

Fuente: elaboración propia.

falta de lo que pueda deparar el porvenir. Máximas humedades, y por ende cambio de signo en la precipitación, en 1920, 1958 (máximo absoluto) y 2003. Los valles más profundos se produjeron en los años 1898 (mínimo absoluto), 1937 y 1988 respectivamente (gráfico 7).

3) Este modelo repetitivo no está presente en el inmediato norte, en concreto ni en las estaciones de Puerto Montt ni Valdivia (gráficos 8 y 9 , respectivamente), en los que predomina una única ola, ascendente al inicio y con máximo en 1930 y 1969 respectivamente, y descenso desde estos máximos casi ininterrumpidamente. Para complicar más la posible explicación, la estación de Osorno, de localización intermedia, muestra un máximo en 1981, y un mínimo en 1934, con oscilaciones más o menos rítmicas, intermedias.

4) Más al norte, en las estaciones de Temuco y Concepción, se mantiene la pauta de una única subida y bajada, alcanzando el máximo en 1951 y 1966 respectivamente. Pero frente a la simplicidad de la curva en Puerto Montt y la Valdivia, muestran una mayor oscilación, tanto en la 
GRÁFICO 8

DESVIACIONES ACUMULADAS EN UNIDADES DE PRECIPITACIÓN PARA PUERTO MONTT

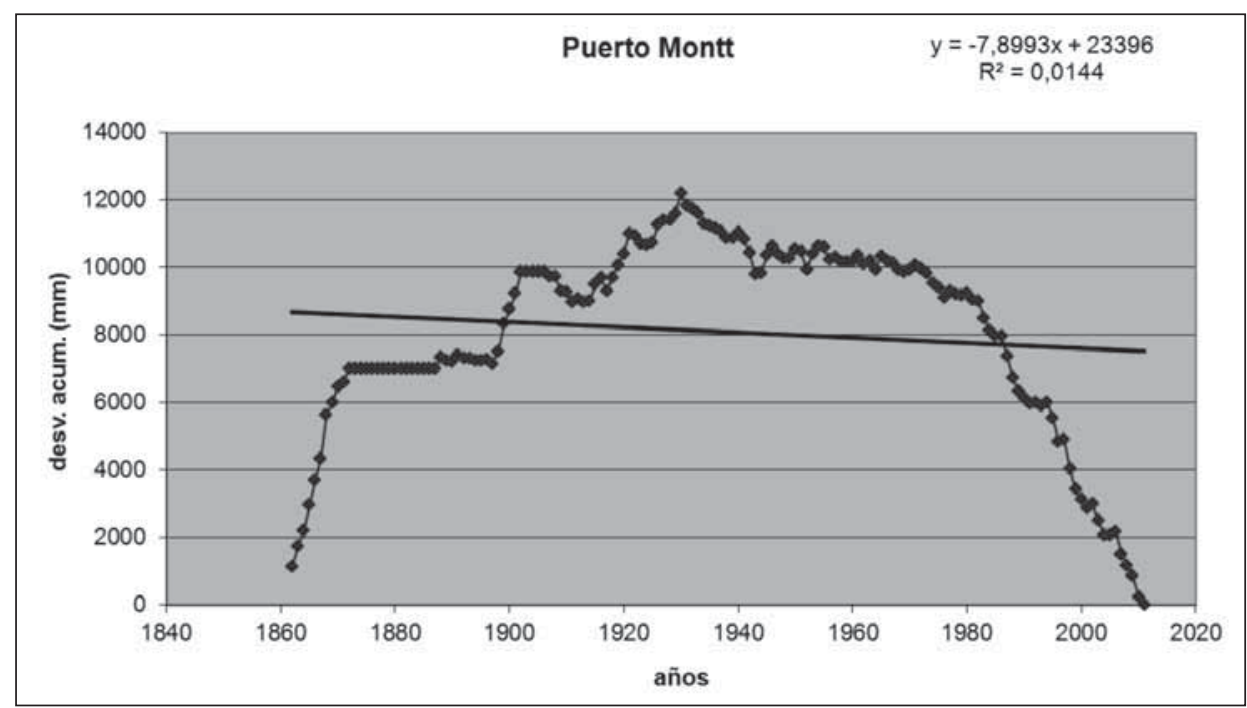

Fuente: elaboración propia.

GRÁFICO 9

DESVIACIONES ACUMULADAS EN UNIDADES DE PRECIPITACIÓN PARA VALDIVIA

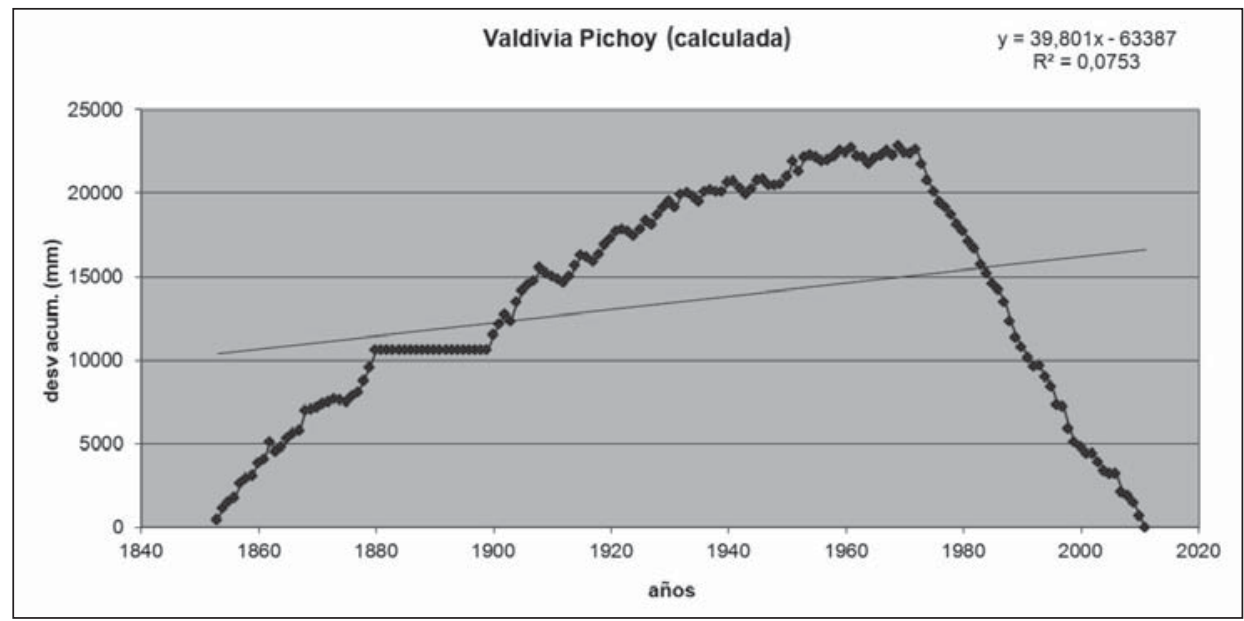

Fuente: elaboración propia. 
rama ascendente como descendente. Curicó más se asemeja a la pauta de Punta Arenas que a las estaciones inmediatas. Con un máximo en 1984 y un mínimo en 1925, tiene oscilaciones entre extremos.

5) Una presentación única es la de la Isla de Juan Fernández o de Robinsón Crusoe, pues muestra un ascenso notable de la humedad en los últimos tiempos: mínimo en el 1971 y máximo secundario en 2009, dado que el máximo absoluto se registró en 1928. Sólo la Isla de Pascua se asemeja con máximo en 1948 y mínimo en 1976, momento desde el que se ha entrado en un lapso de humedad que podría haber tocado a su fin igualmente en 2009. Parece, pues, que las condiciones en el Pacífico son más uniformes que las registradas en el continente, donde los factores locales pueden desempeñar un papel muy importante en la precipitación. Las diferencias más podrían imputarse a la distinta longitud de la serie en ambas islas que a una auténtica diferencia en los patrones de lluvia. Así existe un máximo secundario en 1951 en Juan Fernández, que bien podría corresponderse al de Pascua. Y ello a pesar de la distancia astronómica que las separa: unos $3.035 \mathrm{~km}$ (gráfico 10).

\section{GRÁFICO 10}

COMPARATIVA EN PORCENTAJE DE LAS ESTACIONES ISLEÑAS CHILENAS EN SUS PRECIPITACIONES ACUMULADAS DESVIADAS DE LA MEDIA RESPECTIVA

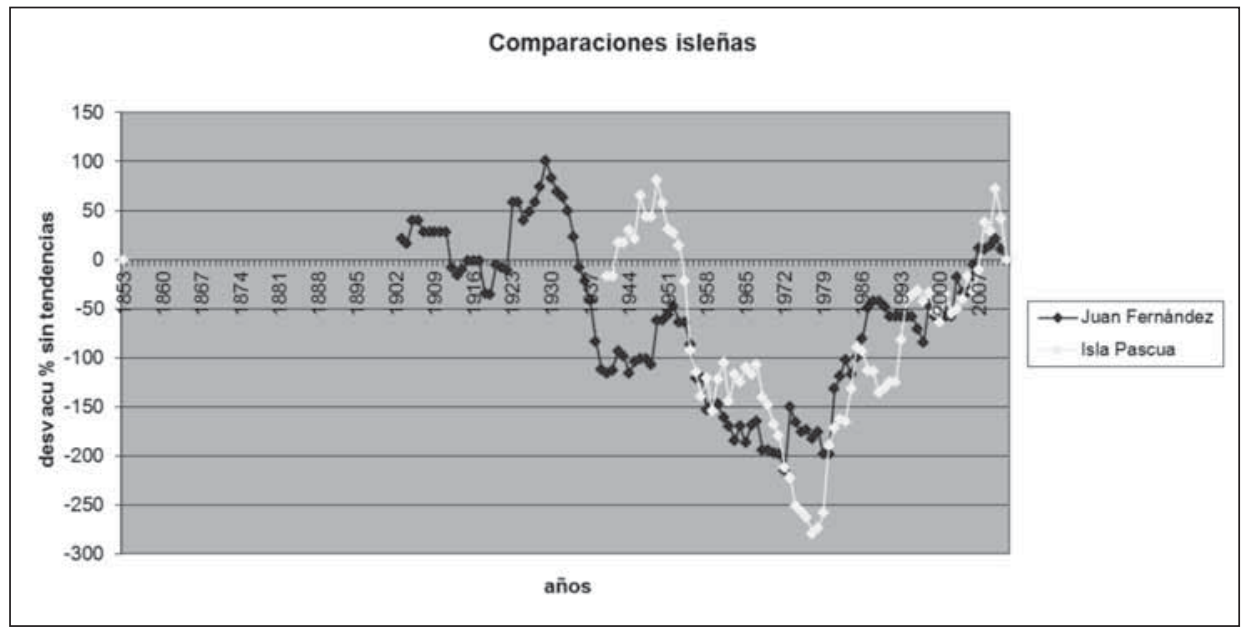

Fuente: elaboración propia.

Estudios Geográficos, Vol. LXXIII, 273, pp. 625-656, julio-diciembre 2012

ISSN: 0014-1496, eISSN: 1988-8546, doi: 10.3989/estgeogr.201222 
6) Santiago ofrece uno de los estudios más completos, dada la longitud de la serie y lo completa que se presenta. Alcanzado el máximo en 1953, la precipitación no ha cesado de reducirse desde entonces. El inicio del período húmedo tuvo lugar en 1879. La estación de La Serena también es harto longeva y su gráfica se asemeja a la capitalina, con mínimos en 1875 y 2010, iniciándose el lapso seco en 1944. ¿Podría comenzar el cambio de tendencia desde el norte para irse desplazando hacia mayores latitudes? De ser cierta esta pauta se explicaría que Antofagasta hubiese alcanzado el valor álgido en 1941, aunque su mínimo de 1922 fuese más difícil de explicar.

7) Aunque ya se ha comentado que el extremo sur, Punta Arenas, posee un modelo "policíclico», que se repite, aunque atenuado, sólo en estaciones más al norte, como Osorno o Curicó, las estaciones intermedias de éstas (Puerto Montt, Temuco, Concepción o Valdivia) ofrecen una pauta «monocíclica», un modelo que ya había caracterizado a ciertas estaciones españolas típicamente mediterráneas (Granada, Mahón, etc.) (Sanz Donaire, 2001). Este hecho podría significar que el modelo mediterráneo está presente en ambos hemisferios, independientemente de su localización precisa. Por otra parte el modelo monocíclico recuerda el trazo de una cicloide, tema sobre el que se volverá más abajo.

8) También cabe destacar que el modelo «policíclico» está más presente en los ámbitos oceánicos españoles (por ejemplo, en San Sebastián), aunque en ningún caso hispano se alcancen las cotas de humedad de los observatorios meridionales chilenos.

9) La comparación entre las estaciones de Copiapó y Antofagasta muestra una progresiva tendencia a la aridez, demostrada a través del aserramiento de la gráfica (Sanz Donaire, 2006), una realidad aún más visible en el extremo norte. Se cumple, pues, la exposición de sierra invertida ya pronosticada.

10) Las estaciones de Copiapó y Antofagasta arrojan una gráfica con dos modelos distintos: el primero de aspecto mediterráneo y, desde 1975 a la actualidad, otro más oscilante. Si se compara con el observatorio de La Serena, inmediato al sur en este trabajo, y teniendo en cuenta que éste es mucho más longevo en registro, cabe pensar dos cosas: o bien el cambio es real en las Regiones II-IV, o bien se observa en los dos primeros sólo un lapso parcial, con ciertos ajustes (a modo de réplicas sísmicas menores, tras la fase álgida del temblor), que también precedieron a la gran ola de precipitaciones, y sólo están visibles en el caso de La Serena (período 1875 a 1925) porque allí hubo registro. 
11) Pero no debe olvidarse la observación con la que se iniciaba este listado: lo más notable es la gran diversidad, máxime en un territorio comprensivo de tanta variedad climática por su extensión meridiana.

Teniendo en cuenta que Punta Arenas muestra además de sucesión de lapsos húmedos y secos una tendencia general significativa de aumento anual de 4,32 $\mathrm{mm}$ de precipitación, pareció apropiado restar esta cifra, multiplicada por el número de años transcurridos desde el origen de la serie, a los sucesivos valores desde el segundo con el fin de «aplanar» la gráfica, pudiendo trabajar más claramente con la componente cíclica de la precipitación. El resultado se ofrece en el gráfico correspondiente (11), en el que se pone de manifiesto que la gráfica es «sin tendencia». Esta misma pauta se ha realizado para Curicó y Osorno (gráfico 12). Por parte de cierta investigadora se ha señalado que «esto hace pensar que los aumentos y disminuciones de lluvias podrían ser parte de procesos naturales que se repiten cada cierto tiempo y no necesariamente son parte de un cambio climático» (Cornejo Saldías, 2011, p. 72).

Es muy llamativo, pero algo bien propio de los ambientes áridos, que las desviaciones acumuladas de las distintas estaciones de observación se amplíen conforme el clima resulte más árido. Mientras Arica e Iquique ostentan rangos porcentuales acumulados de -5000 a 2100 , las islas barren valores de $100 \%$

\section{GRÁFICO 11}

DESVIACIONES ACUMULADAS EN PORCENTAJE RESPECTO DEL VALOR MEDIO DE LA SERIE DE PUNTA ARENAS UNA VEZ RESTADA LA TENDENCIA

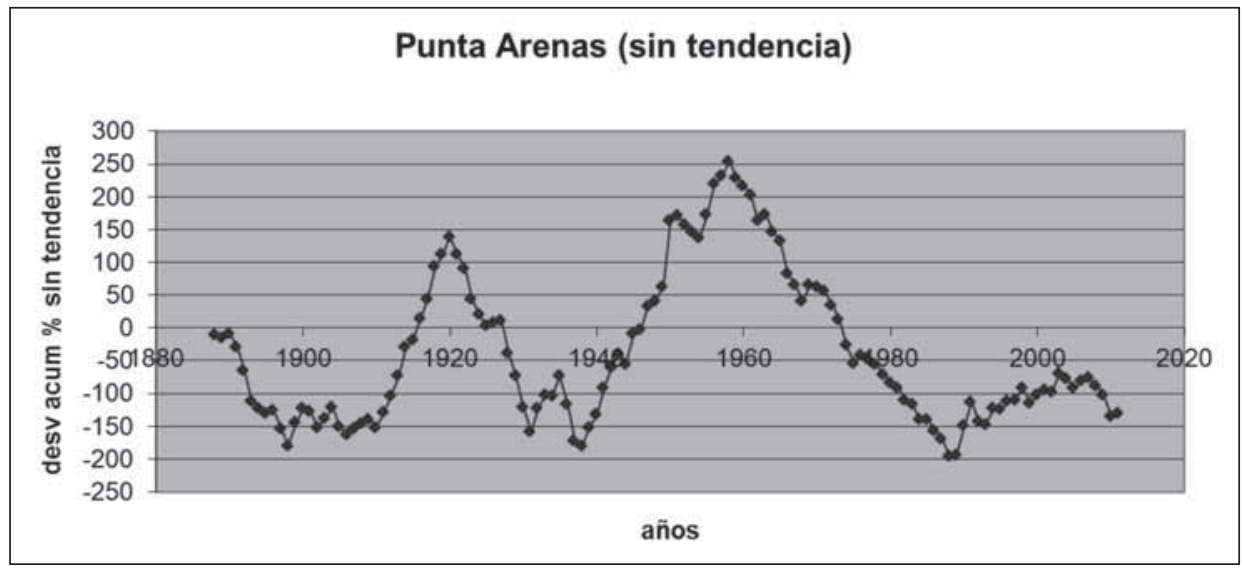

Fuente: elaboración propia. 
GRÁFICO 12

PAUTA OSCILANTE DE LA PRECIPITACIÓN DE OSORNO, A LA QUE SE LE HA RESTADO LA TENDENCIA ALCISTA

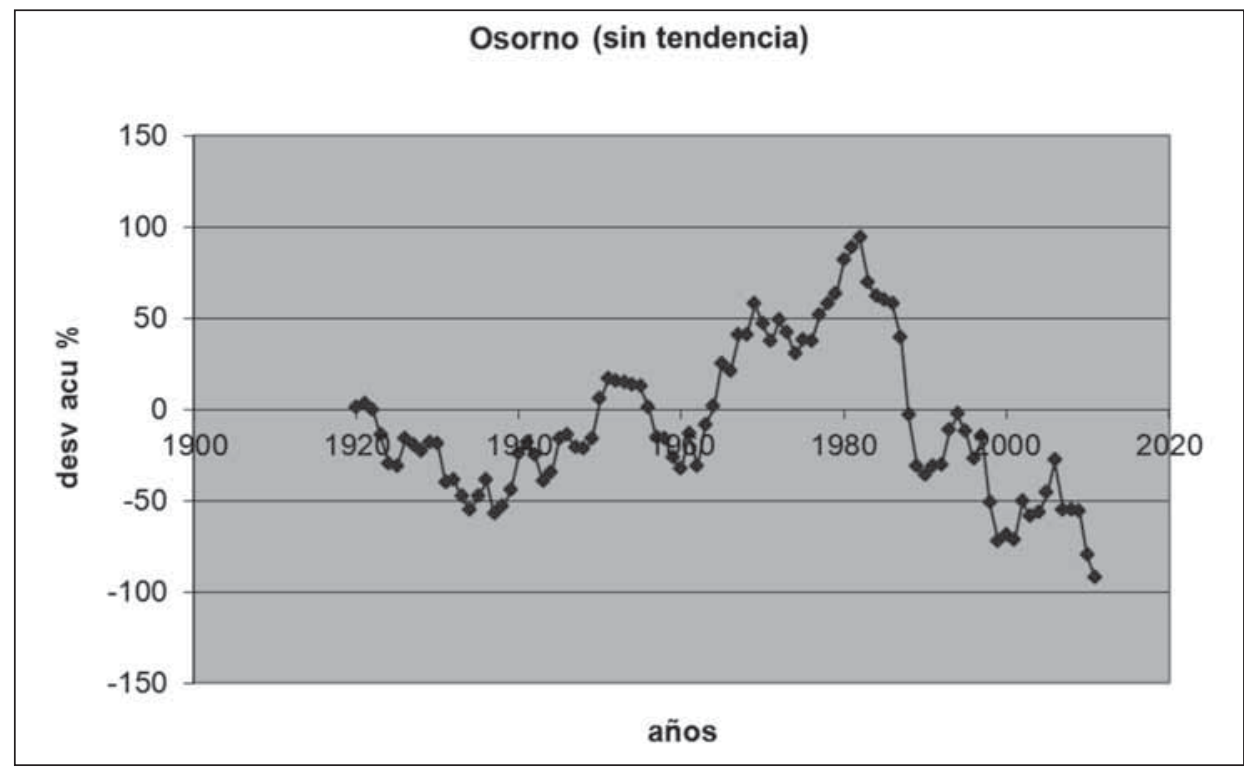

Fuente: elaboración propia.

a $-275 \%$. Y, aunque en los valores extremos acumulados también desempeña un papel importante la longitud de la serie (así Valdivia, la más longeva de entre las húmedas, es la estación más sobresaliente con un máximo de 960\%), es la propia naturaleza de la variación la que más influye en la gráfica final ${ }^{1}$.

En apoyo del comportamiento de los lugares progresivamente más áridos están los casos comparados de Santiago y La Serena: aquí la serie es igual de larga, por lo que no cabe recurrir a este hecho para explicar las diferencias. Sin embargo, La Serena tiene unos máximos más altos que Santiago, corroborándose la afirmación anterior de que la creciente aridez amplifica los máximos. Sin embargo no se puede decir lo mismo de los mínimos, en los que prácticamente coinciden, al menos en valor, ambas estaciones: Santiago -80; La Serena -50 , si bien dichos mínimos se hallan en el primer caso a comienzos de la serie y en el segundo al final.

\footnotetext{
${ }^{1}$ Un caso paradigmático es la estación de Punta Arenas, una de las estaciones más oscilante, muy apropiada para un análisis sinusoidal.
} 


\section{ESTUDIO DE PERIODICIDADES}

Sobre la base de que estamos trabajando con un subsistema del sistema climático, esto es, de que la precipitación como sistema tiende a la autorregulación con tal de que no se sobrepasen unos umbrales - ya experimentales, ya teóricos-, cuya definición está todavía por realizar, considero que — como ya se dijo más arriba-, no tiene sentido encapsularse en unos modelos lineales, que por su simpleza - y máxime si se quiere continuarlos a futuro-, presentarían cambios en principio excesivos, no compatibles con la filosofía sistémica, hoy tan afianzada, ni con unos resultados poco creíbles. Así pues se ha intentado ajustar curvas de tipo sinusoidal a los valores elaborados, las únicas que, creemos, tendrían sustento en la realidad.

El ajuste de una curva en los datos de Punta Arenas, candidata a este tratamiento desde que se inició el estudio a tenor del trazado que representaban las gráficas, se ha realizado en dos fases: la primera ha supuesto la resta de la línea de tendencia que, obviamente, complicaba el análisis. El resultado final es el siguiente (gráfica 13):

GRÁFICO 13

AJUSTE DE UNA SINOSOIDAL A LOS VALORES DE DESVIACIÓN ACUMULADA RESPECTO DE LA MEDIA EXPRESADA EN MILÍMETROS DE PRECIPITACIÓN

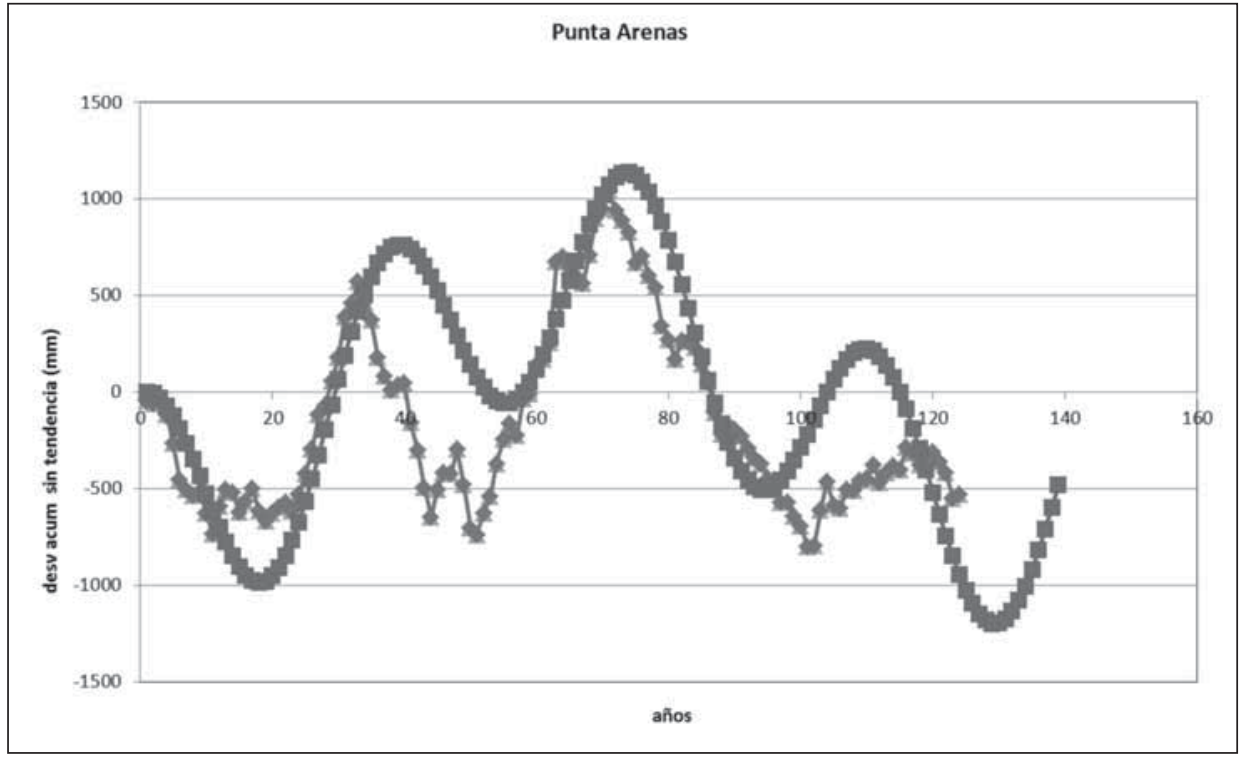

Fuente: elaboración propia.

Estudios Geográficos, Vol. LXXIII, 273, pp. 625-656, julio-diciembre 2012 ISSN: 0014-1496, eISSN: 1988-8546, doi: 10.3989/estgeogr.201222 
La expresión utilizada ha sido:

En donde:

$$
y=1200 \operatorname{sen}\left(2 \pi \frac{x}{103}\right) \operatorname{sen}\left(2 \pi \frac{2}{57}\right)
$$

- y = valor estimado de la precipitación en años a partir de 1888 .

- $\mathrm{x}=$ (número de años transcurridos desde 1888) - 1888.

Se ha medido el grado de ajuste entre los valores calculados y los reales mediante el coeficiente $\mathrm{R}^{2}$, lo que arroja un valor bastante elevado del 55,57\%.

Los valores de ciclo introducidos en la fórmula sinusoidal no coinciden con los hallados en los datos elaborados como desviación de la media de todo el período, dado que el periodograma dio unos máximos a 124, 41,3 y 31 años muy claros, y unas señales mínimas a 8,8, 7,3 y 6,2 años.

Si la estimación fuera próxima a la realidad cabría pues esperar la continuación del descenso de precipitaciones hasta 2016 para comenzar a partir de entonces una remontada, aunque en cualquier caso la incertidumbre año a año fuese alta.

La contemplación de los casos monocíclicos recuerda el desarrollo de las curvas cicloides. Como se sabe son aquéllas que se originan al hacer rodar un punto de un círculo sobre una recta. Su aspecto es tanto más en arcada casi semicircular o arco tipo carpanel, según dónde se sitúe el punto en cuestión: si en la circunferencia delimitante del círculo o dentro del mismo. No obstante la intención inicial de modelizar el comportamiento de Puerto Montt, Temuco o de Concepción mediante esta expresión, la realidad física hace imposible su aplicación: en efecto podría ajustarse una cicloide, pero no tiene sentido dado que las variaciones, una vez alcanzada la recta directriz, también llamada recta base, sería, para los casos mencionado en los que llueve cantidades importantes, más una recuperación - ¿lenta? — que no un salto hacia arriba con aspecto de signo zodiacal Aries. Así, por cierto, lo demuestran los gráficos que se pueden construir de las series de precipitación más largas de la Tierra y en lugares bien apartados por su geografía: de Berlín, de Seúl o para el clima monzónico de Cherrapundji (India). Por otra parte el ajuste de una cicloide no deja de ser un caso extremo de una repetición cíclica. Existe además un segundo inconveniente: la apariencia en arcada es fruto preferente del tratamiento mediante desviaciones respecto de la media, más que de los datos en sí. Como se sabe las curvas de desviaciones acumuladas que estén correctamente construidas deben terminar necesariamente en 0 ó en un valor infinitesimalmente próximo a él. De ahí que, como también en su comienzo procedan desde un valor cercano a la media, en los análisis de los periodogramas se destaque tanto el ciclo completo, hasta el punto de enmascarar los restantes componentes cíclicos. 
El tercer argumento se asienta sobre la comparación de estos modelos monocíclicos con las estaciones más longevas, no ya del Globo, sino del propio Chile: la curva de Santiago tiene un aspecto bastante coincidente con las mencionadas anteriormente (gráfico 14), si bien, merced a su más largo registro, ofrece un aspecto sinusoidal incompleto, pero ciertamente sugerente (gráfico 15).

\section{GRÁFICOS 14 Y 15}

CURVA ACUMULADA DE DESVIACIONES DE PRECIPITACIÓN PARA SANTIAGO DE CHILE CON AJUSTE SINUSOIDAL INFERIOR
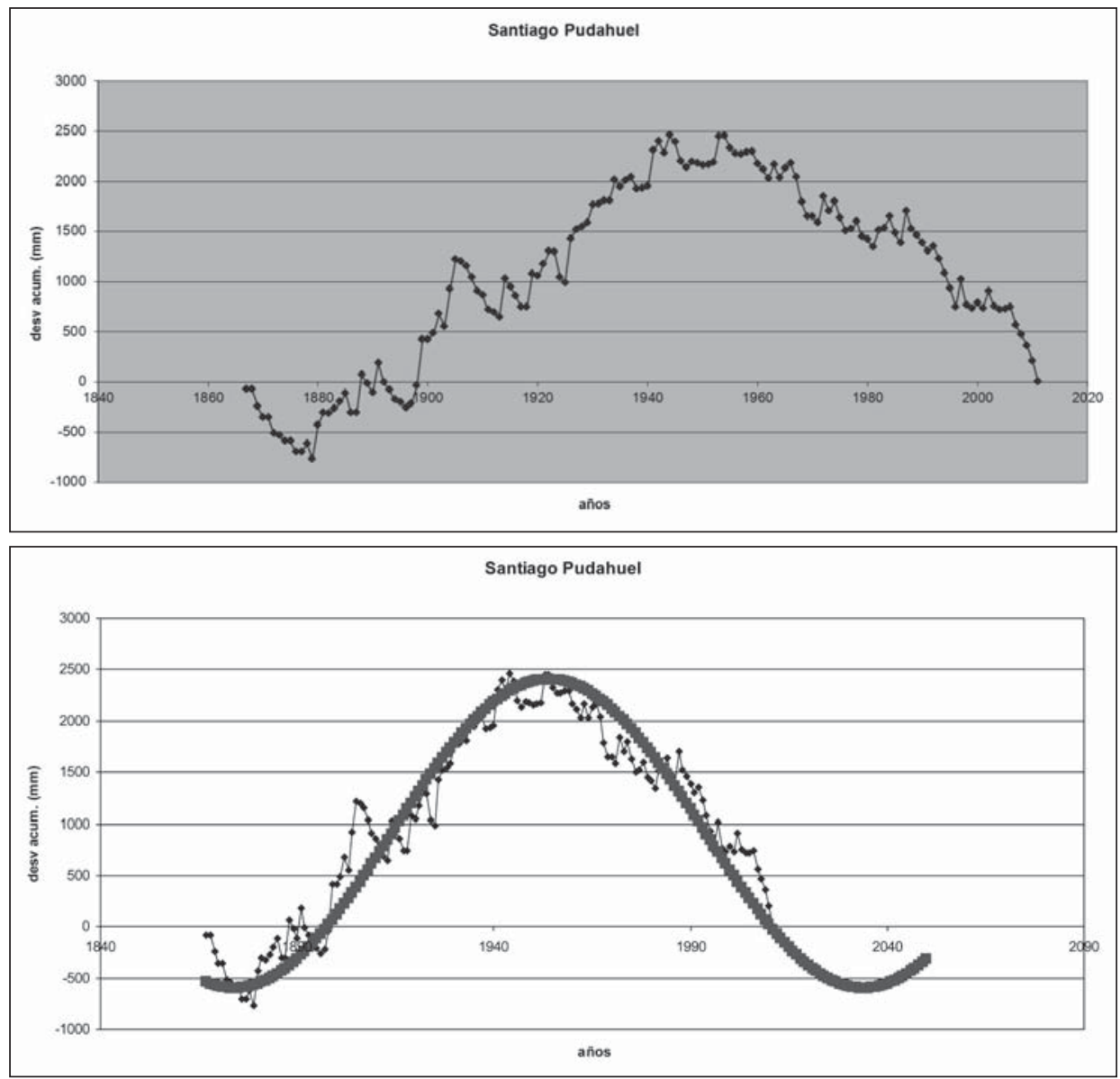

Fuente: elaboración propia.

Estudios Geográficos, Vol. LXXIII, 273, pp. 625-656, julio-diciembre 2012 ISSN: 0014-1496, eISSN: 1988-8546, doi: 10.3989/estgeogr.201222 
La fórmula que explicaría la mayor parte de la variación, hasta alcanzar un coeficiente de determinación o $\mathrm{R}^{2}$ del 95,06\% sería la que sigue:

$$
y=1500 \operatorname{sen} \frac{2 \pi(x-1754)}{160}+904
$$

En donde:

- 1.500 , representa la semiamplitud.

- 160 , el periodo.

- 904, la altura.

- x, la fecha en años d. J. C.

Finalmente existe un cuarto inconveniente, también físico, de la posible aplicación de una cicloide a los datos monocíclicos chilenos: ¿qué significado real tendría el modelo cicloide a estaciones como Puerto Montt o Curicó? Una primera razón podría estribar en que los ciclos topasen con un umbral intransgredible. Buscando en la realidad habría de ser un obstáculo geográfico como una cadena montañosa, o incluso otro astronómico como el Círculo Polar Antártico —umbral de las «noches poliheméricas ${ }^{2} »-$. También podría argumentarse a favor de que el extremo meridional de la masa continental americana da paso a los roaring 60's, aquí desplazados ligeramente al norte, por lo que más propiamente cabría hablar de los roaring 50's, un límite que más debiera afectar al gráfico de Punta Arenas que a aquéllos en los que realmente se encuentra. Más aún: Punta Arenas tendría más consideración hacia el Atlántico que hacia el Pacífico, si nos atenemos a su localización respecto de las máximas altitudes (cimas casi perpetuamente nevadas sembradas de glaciares) que servirían como línea de cumbres para delimitar las vertientes pacífica y atlántica. ¿Pero qué umbral es ése que está presente en distintas latitudes sin aparente manifestación geográfica? Más aún, ¿qué umbral se patentiza como enclaves en el interior de un dominio de las curvas sinusoidales? ¿No será, más bien, una construcción del tratamiento dado a los datos, porque la gráfica necesariamente ha de terminar en 0 ? Si se tratase de un umbral físico, desconozco la respuesta a la primera pregunta.

Para Osorno los periodogramas dan ciclos de 92, 46, 15,3, 10,2 y 5,1 años, si bien para Curicó arrojan 46, 23, 10,2, 7,1 y 5,1 años. La Isla de Juan

\footnotetext{
${ }^{2}$ He creado este neologismo para referirme a las noches de varios días (de 24 horas), a fin de evitar largos circunloquios.
} 
Fernández el consabido ciclo de toda la serie, 110, 27,5 y mucho más atenuado 6,5 años. Santiago, además de la longitud de toda la serie (145 años), sólo 48,3. Sin embargo de la observación visual de la curva acumulada parece vislumbrarse una cierta repetición cada 10 años, lo que se ha puesto de manifiesto por parte de Aceituno (1992), entre otros. La Serena 143, 35,8 y 23,8 años.

Los periodogramas, en fin, no permiten apreciar un comportamiento uniforme en las distintas estaciones, lo que, una vez más, denota aleatoriedad en la respuesta pluviométrica, condicionada por tal cantidad de factores que resultan inabarcables y empujan a la consideración de este meteoro como impredecible o estocástico.

No obstante y como afirma el Informe Variabilidad climática chilena para el siglo XXI (p. 45), «en el Norte Chico el incremento de las precipitaciones extiende su dominio bajo el escenario B2 abarcando toda la faja del territorio chileno entre los 20 y $33^{\circ} S_{»}$, también mediante las curvas aquí descritas para La Serena (así Pérez Valdivia, 2005 cita una bajada del 40\%, aunque compensada por la mayor precipitación en los Andes inmediatos) y para Copiapó se establece el mismo futuro, sin entrar en variaciones estacionales. La Región Central de Santiago en el mencionado informe denota «una pérdida generalizada de precipitación bajo el escenario A2, condición que se mantiene en el escenario B2», algo que no pensamos se vaya a prolongar dada la posición actual de la curva, a la espera de una remontada cercana en el tiempo. Debe, sin embargo, tenerse en cuenta que el citado Informe salió a la luz en 2006, si bien las previsiones se hacían para dos períodos, 2011-2030 y 2046-2065. Aquí nos referimos más al primero que al segundo. El Sur probablemente perderá al comienzo o se elevará ligeramente, a tenor de las curvas ajustadas a Temuco, Concepción, Valdivia, Osorno y Puerto Montt, lo que también refleja el Informe con la siguiente redacción: «La Región Sur exhibe una transición hacia los montos del Clima Actual» (p. 45). A idénticas conclusiones llega Pezoa (2003, p. 94). La Región Austral, a través de las consideraciones de Punta Arenas, aumentará su cuantía de precipitación y como reza el citado Informe "presenta [...] un leve aumento en el extremo sur que prevalece todo el año» (p. 45).

Así, también los datos aquí aportados son compatibles con los análisis de Quintana (2004) o Quintana y Aceituno (2006), y tienen a su favor la simplicidad y rapidez de cálculo.

Fecha de recepción: 26/09/2012

Fecha de aceptación: 16/10/2012 


\section{BIBLIOGRAFÍA}

Aceituno, P.; Fuenzalida, H. and Rosenbluth, B. (1992): "Climate along the extratropical West coast of South America", in H. A. Mooney; B. Kronberg and E. R. Fuentes (eds.): Earth Systems responses to global change. Michigan, Academic Press, pp. 61-69.

Bown González, F:: "Cambios climáticos en la Región de Los Lagos y respuestas recientes del Glaciar Casa Pangue (410'ㅇ)". Tesis para optar al grado de Magister en Geografía. Universidad de Chile, Facultad de Arquitectura y Urbanismo, Escuela de Postgrado, Departamento de Geografía, 2004. Disponible en: http://www.glaciologia.cl/textos/bown.pdf (Fecha de consulta: 15/08/2012).

CONAMA (2006): Estudio de la variabilidad climática en Chile para el Siglo XXI. Informe Final. Santiago de Chile, Universidad de Chile, Departamento de Geofísica de la Facultad de Ciencias, Físicas y Matemáticas.

Cornejo Saldías, C. G. (2011): "Análisis de la distribución temporal de las precipitaciones en la Región del Maule”. Tesis para optar al título de Ingeniero Forestal. Universidad de Talca, Facultad de Ciencias Forestales, Escuela de Ingeniería Forestal.

Pérez Valdivia, C.A. (2005): "Cambio climático: vulnerabilidad, adaptación y rol institucional. Estudio de casos en el Valle de Elqui". Memoria para optar al título de Ingeniero Ambiental. Universidad de La Serena, Facultad de Ingeniería, Departamento de Ingeniería de Minas.

Pezoa, L. (2003): "Recopilación y análisis de la variación de las temperaturas (período 1965-2001) y las precipitaciones (período 1931-2001) a partir de la información de estaciones meteorológicas de Chile entre los $33^{\circ}$ y $53^{\circ}$ de latitud Sur". Tesis de Máster. Universidad Austral de Chile, Facultad de Ciencias Forestales.

Quintana J. y Aceituno, P. (2006): "Trends and interdecadal variability of rainfall in Chile". Proceedings of 8 ICSHMO, April 24-28, pp. 371-372.

Quintana, J. (2004): "Estudio de los factores que explican la variabilidad de la precipitación en Chile en escalas de tiempo interdecadal". Tesis de Magíster en Geofísica. Universidad de Chile, Facultad de Ciencias Físicas y Matemáticas, Escuela de Postgrado.

Rutllant, J. A. (2004): "Aspectos de la circulación atmosférica de gran escala asociada al ciclo ENOS 1997-1999 y sus consecuencias en el régimen de precipitación en Chile Central", en S. Avarias; J. Carrasco; J. Rutllant y E. Yáñez (eds.): El Niño-La Niña 1997-2000. Sus Efectos en Chile. Valparaíso, CONA, pp. 61-76.

Santibáñez, F. (1997): "Tendencias seculares de la precipitación en Chile", en G. Soto y F. Ulloa (eds.): Diagnóstico de la desertificación en Chile: 31. Santiago de Chile, Corporación Nacional Forestal.

Sanz Donaire, J. J. (2001): "Cambios aleatorios de precipitación española en la fase instrumental”, en A. J. Pérez Cueva; E. López Baeza y J. Tamayo Carmona (eds.): El tiempo del clima. Publicaciones de la Asociación Española de Climatología (AEC). Serie A, no 2, Valencia, pp. 219-233. 
Sanz Donaire, J. J. (2006): "La problemática de las precipitaciones en el marco del cambio climático. En Mitos y realidades del cambio climático". Revista del Instituto de Estudios Económicos, 3-4, pp. 25-75.

Valdés, R. (2009): "Análisis del comportamiento temporal y espacial de las precipitaciones en la Región de Los Ríos, Región de Los Lagos y Región de Aysén". Memoria para optar al título de Ingeniero Forestal. Universidad de Talca, Facultad de Ciencias forestales, Escuela de Ingeniería Forestal.

\section{Informaciones electrónicas}

Anuarios Climatológicos de Chile, 1920-2012. Dirección Meteorológica de Chile, Subdepartamento de Climatología y Meteorología Aplicada. Disponible en: http://164.77.222.61/climatologia/ (Fecha de consulta: 15/08/2012).

\section{RESUMEN}

En el presente trabajo se hace un estudio de las precipitaciones anuales de las 15 estaciones con registro más largo de Chile. Se plantea la evolución para todo el período instrumental, y para los treintenios CLINO. Los resultados se ofrecen a través de rectas de regresión con su pendiente y valor de probabilidad. Finalmente se introduce en un análisis sinusoidal, más acorde con la noción actual de sistema climático.

PAlabras Clave: Chile; precipitación; análisis sinusoidal; cambio climático.

\section{Abstract}

This paper studies the annual precipitation of the 15 stations with the longest registry in Chile. It analyzes the evolution for the entire instrumental period, and for the CLINO thirty-year periods. The results are offered through regression lines with their slopes and probability values. Finally, it is submitted to a sinusoidal analysis, which is more in line with the current interpretation of climate system.

KEY WORDS: Chile; precipitation; sinusoidal analysis; climate change.

\section{RÉSUMÉ}

Cet article fait une étude des précipitations annuelles des 15 stations météorologiques disposant des registres les plus longs du Chili. L'évolution est envisagée pour l'ensemble de la période instrumentale et pour les périodes de trente ans CLINO. Les résultats sont proposés à travers des lignes de régression avec leur pentes et leur valeurs de probabilité. Finalement, il amorce une analyse sinusoïdale plus conforme à la notion actuelle de système climatique.

MoT CLÉS: Chili; précipitation; analyse sinusoidale; changement clímatique. 


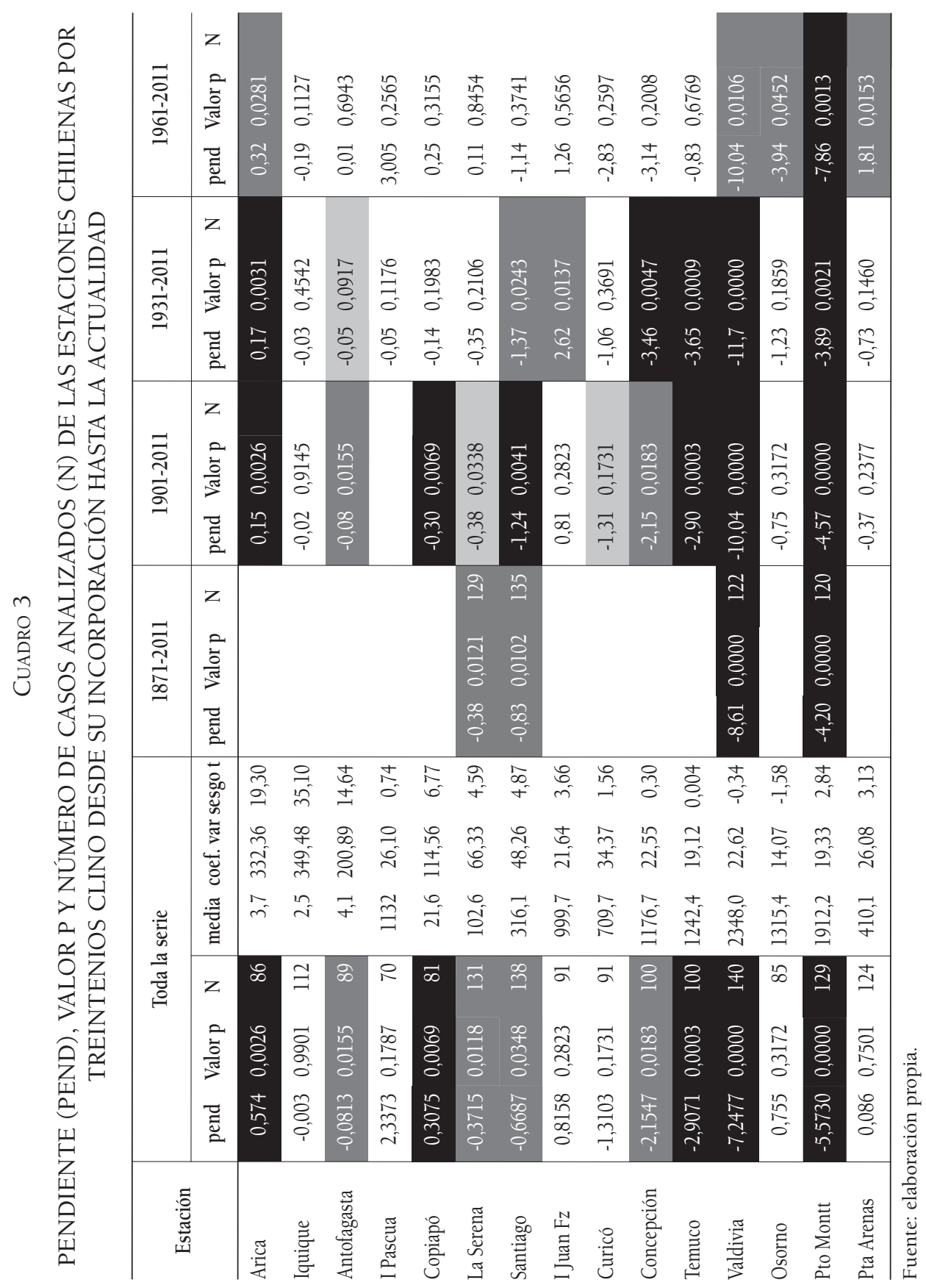

Estudios Geográficos, Vol. LXXIII, 273, pp. 625-656, julio-diciembre 2012 ISSN: 0014-1496, eISSN: 1988-8546, doi: 10.3989/estgeogr.201222 


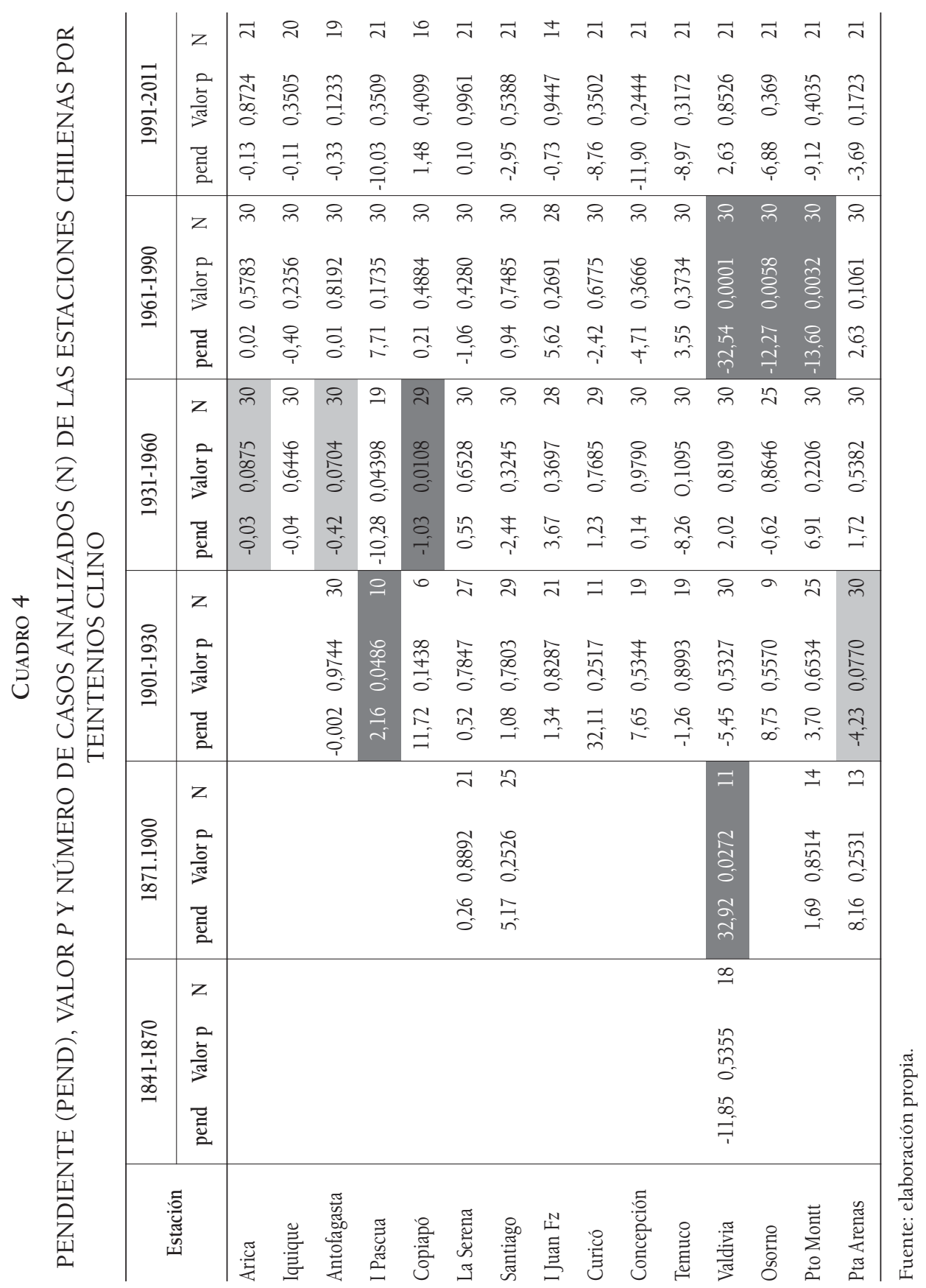

Estudios Geográficos, Vol. LXXIII, 273, pp. 625-656, julio-diciembre 2012 ISSN: 0014-1496, eISSN: 1988-8546, doi: 10.3989/estgeogr.201222 